\title{
Valuation of Morality and Mind: Morality as a Metacognitive Byproduct
}

\author{
Richard Baxter*,o \\ ‘2915/350 William St, Melbourne VIC 3000, Australia \\ * richardbrucebaxter@gmail.com
}

\begin{abstract}
The organism has evolved to view itself as a sentient being. It is theorised that morality is a byproduct of the high valuation of mental properties (the nature of its theory of mind). Five studies were conducted with 2675 participants. A positive association was confirmed between valuation of explicit morality, neutral (general) mind as measured by sentience, and significance of (specific) mind as measured by integrity (1). The moral worth ratings of a protagonist were affected by manipulating perceived significance of mind as expressed by scope and intensity of thought (2). $50 \%$ of participants thought morality applies exclusively to creatures with minds (3). A positive association was found between the self-awareness and moral worth ratings of a variety of creatures and human characters (4). Furthermore, the moral worth ratings of a human being and 'philosophical phantom' (sentient inanimate object) were greater than those of a philosophical zombie and rock (5). Like H. Gray et al. [1], this research suggests that morality is based on the belief in mind (1-5). Specifically, the results suggest that valuation of experience (sentience) and agency (significance of mind) are not independent, as assignment of morality appears preconditioned upon the perception of (or assumption of) sentience (5). Furthermore, contrary to dyadic models [2], preliminary analysis supported the prediction of self and other-directed morality (1).
\end{abstract}

\section{Author Summary}

\section{Introduction}

"Because if a machine can learn the value of human life, maybe we can too." [3]

There has been much research in the moral psychology literature in terms of how people make ostensibly moral judgements, yet there has been less with respect to how people define morality; what people associate explicit morality with. It is theorised that although evolutionary adaptations play a role in behaviours often associated by researchers with morality (e.g. [4]; intuitionist model), morality is not reducible to arational behaviour, being dependent on the intention associated with behaviour. Morality is hypothesised to be a cognitive artefact of the development of systems associated with the organism's theory of mind (in the context of existential belief) and its nurture by society. Specifically, it is proposed that morality as commonly understood is a byproduct of human beings viewing mind as something over and above the physical (observables), and the conclusion that such demands both special treatment and action (significance). Note the truth of this belief (whether the neural activity representing the 
self corresponds to a real sentient being; is mapped to mental properties or phenomenological consciousness) is not an empirical question and one hereafter ignored.

This general hypothesis has been developed on a number of grounds; (1) a growing literature concerning theory of mind and morality, (2) limitations within existing theories of descriptive morality, (3) a lack of research distinguishing moral from amoral behaviours or motivation, (4) the consequences of the evolutionary development of an internal representation of self, and (5) the coevolution of extra-group morality with our discovery of a common humanity (see S1 Appendix). Developmental, neuroscientific, and cross-cultural research can be used to identify innate psychological mechanisms, and were therefore focused on in this analysis.

Firstly, there is a growing literature on theory of mind with respect to morality (e.g. [5]), including the importance of cognitive empathy (e.g. [6]). People's evaluation of their theory of mind must however be researched in this context. Secondly, the intuitions and emotions identified by contemporary accounts of morality (e.g. 7]) might be socialised. Likewise, they compete with other adaptations, and their modularisation is difficult to reconcile with current neuroscience [8]. Furthermore, existing experimentation might fail to capture scenarios in which the evaluation of mind plays a greater role (the active negation of decidedly immoral acts). There has however been speculation that (cognitive) empathy and therefore morality might be a byproduct of adaptive theory of mind [9].

Thirdly, the moral classification of behaviour may be dependent on the motive of the act [10, 11]. Similarly, theory must be able to account for the fact human immorality is often closely tied to morality (e.g. revenge, [12]), and is not simply the absence of morality. Fourthly, the human being does not just view itself as an information processing system; it has evolved to view itself as a sentient being that transcends the material construct (even eliminativists maintain the intuition). This belief constitutes the nature of its theory of mind. The implications of our belief concerning the nature and significance of mind are in general under-researched, and are often tied to specific philosophies of mind (e.g. [13]).

Fifthly, it is argued that although affective empathy can be considered interrelated to cognitive empathy on the basis of their underlying neural networks (mirror neurons; [14]), any adaptive (arational) account of cross-cultural morality is considered unlikely due to its nullification of moral authority, and its dependence on the health [15] and application of dedicated emotional systems. Furthermore, arguments have been made for and against animal rights on the basis of their sentience (e.g. [16]).

\section{Morality as a metacognitive byproduct}

A cognitive basis for morality is both self-awareness and the projection of one's self-awareness to another. The brain is biologically programmed (through evolutionary adaptation) to be aware of itself (ourself), and is at least capable of awareness of other humans (selves), as 'subject' (the nature of its theory of mind). Subject can be understood here as a not-only-physical being (entity), where physical is used here in the empirical sense of observables; not in the philosophical sense of physicalism [17. It is hypothesised that morality is a byproduct of the organism's high valuation of its own (theoretical) mind, and the logical extension of this belief to like others. Morality is therefore seen as a metacognitive artefact, or a consequence of viewing oneself as a cognitive creature [18].

From our brain's view of self as a subject, we may have a sense of appreciation of self (worth), and consequently demand our moral treatment. We are also capable of gaining a sense of appreciation of the subjective worth of others (based on a logical projection of our own mind's physical dependence), which too places rational demands on moral treatment (action). Furthermore, it is possible that sense of self demands moral action 
directly, as if such a being were to only expect certain treatment-irrespective of its own actions-then it would lessen its sense of worth as a subject (by questioning its qualities as an agent). Such action would lessen its belief in self. Likewise, although immorality often derives from the same motivations as morality, it is contradictory (contradicts accepted beliefs regarding the significance of one's own mind, and that of others). As such, cognitive dissonance might account for its historic association with wretchedness [19 21. Therefore under this model, sense of self is opposed to both immoral treatment and action, while being enhanced by especially moral treatment and action (morale).

Such a system of morality is reliant on cognitive empathy, but operates on the belief in the value of mind itself (not just its experience; e.g. pain). Mind is valued based on both its sentient qualities (neutral mind), and those qualities which mark its respect for sentience (being indicative of a greater significance of mind). Although general (common) mind is valued only for its neutral sentience, a specific mind may be valued based on whether it acts in accordance with a high valuation of general mind (i.e. whether mental processing is devoted to respect for self and others); in addition to its neutral sentience. Significance of mind is interpreted here as being preconditioned upon sentience: without sentience (or the capacity thereof), a mind cannot be viewed as morally significant (irrespective of its agency). The model of morality is detailed in S5 Appendix, including its predictions for self and other-directed morality (which are not discussed in the main text).

\section{Relationship to existing theoretical constructs}

Existing research has identified a strong connection between morality and mind. The 'experience' and 'agency' constructs of H. Gray et al. [1], along with the 'human nature' and 'human uniqueness' constructs of Haslam [22], align closely with neutral mind (sentience) and significance of mind respectively. Neutral mind maps directly to experience, and is primarily a subset of human nature (albeit incorporating human uniqueness to some degree, in that it does not preclude experience of refined emotions). Likewise, human uniqueness and agency are the subset of significance of mind not captured by neutral mind. Experience and agency are aligned with 'moral patiency' and 'moral agency' respectively [1, both of which have been argued here as a consequence of belief in mind (the demand for moral treatment and action).

Furthermore, H. Gray et al. [1 have confirmed that morality relates to the valuation of mind. Gray et al. 2] even concluded it to be a consequence of the perception of mind. Yet it is not clear as to the specific nature of the theory of mind being valuated. It was originally framed to accommodate eliminativist perspectives on mind, including that of Dennett 23. Likewise, it has been argued that mind perception occurs along two independent dimensions (experience and agency) 1, 2, 24. Differing from this analysis, significance of mind is interpreted as being preconditioned upon neutral mind (outlined previously). Morality should therefore be critically dependent on the perception and valuation of neutral mind.

Accordingly, this work represents an independent derivation (from evolutionary first principles) of these constructs in relation to morality. As such, it may provide a new

theoretical framework for their interpretation. Furthermore, it tests the strength of both sentience and significance of mind in moral judgement, using a variety of measures and designs. It concludes by exposing the predictive power of the underlying theory; testing whether morality is based specifically on the belief in existential mind (mental properties). 


\section{Studies}

In order to examine the theory, five studies were conducted. These studies measured the association between valuation of neutral mind and morality, along with the association between valuation of significance of mind and morality (1). They also measured the moral worth ratings of a protagonist after manipulating their perceived significance of mind (2). Furthermore, they collated definitions of integrity, and queried whether participants thought morality applies exclusively to creatures with minds (3). Finally, they determined whether moral worth and self-awareness ratings for a set of creatures were correlated (4), and compared the moral worth ratings of a human being with that of a philosophical zombie, philosophical phantom, and rock (5).

Thus, these studies measured a general valuation of morality and its association with both a general valuation of general mind and a general valuation of significance of mind (1), manipulated the valuation of specific mind (significance of mind) while measuring valuation of morality (2), measured the exclusivity of the application of morality to creatures with mind (3), measured valuation of both general and specific mind (significance of mind) and its association with valuation of morality (4), and manipulated valuation of general mind while measuring valuation of morality (5).

The first four studies (1-4) were designed to test the association between valuation of explicit morality, neutral mind, and significance of mind. The fifth study (5) was designed to specifically test the dependence of morality on existential mind (mental properties). All measures of morality used were explicit, for the purposes of analysing the construct (independent of researcher opinions on the nature of morality).

The first study (1) was also designed to allow preliminary testing of the model's predictions for self and other-directed morality.

Data were obtained using the crowd source service CrowdFlower. The first study (1) was conducted with both international (150) and USA (1275) participants, and the third study (3) was conducted with both international (84) and USA (416) participants. All remaining studies $(2,4,5)$ were conducted with USA participants only. A total of 2675 participants contributed to the studies (2058 final; after performance filtering). Some participants contributed to multiple studies, but their data were not excluded from the analysis. Out of the total 2675 (2058 final) participants surveyed, 1265 (959 final) were identified as being unique (as determined by their CrowdFlower Worker IDs). All primary analyses were verified to hold with unique participants also.

Ethics approval by an ethics committee was not required for the studies (they are classified as negligible risk research according to the NHMRC). CrowdFlower contributors (and those of associated channels) voluntarily completed an electronic survey titled "(Basic) Values Survey". They were provided task instructions before completing the survey, and were informed by the crowd source program that they were only paid if they completed the survey. They were also informed by the crowd source program that they could exit at any time (e.g. "If you'd like to try another task or would rather go enjoy the sunshine, you can leave a task at any time by clicking here"). The data were obtained and analysed anonymously.

\section{Study 1}

Study 1 was conducted in six parts (P1 to P6). Each part measured morality as a value, valuation of neutral mind (P1: mind, P2: sentience/consciousness, P3: mind/awareness, P4: yourself/existence, P5: mind/consciousness, P6: mind/sentience), and valuation of significance of mind (P1: integrity, P2: integrity, P3: integrity, P4: being true to yourself and others, P5: integrity, P6: integrity, contemplation, conscience, not thinking about others). The measures of significance of mind were non-exclusively dyadic 
(integrity and being true to yourself and others), although P6 introduced additional purity foundation neutral self-directed (contemplation, conscience) and negative (not thinking about others) measures. Note integrity has been associated with a concept of purity in Moral Foundations theory [25], and was assumed here to be non-exclusively dyadic (other-directed). It was hypothesised (1A) that people's valuation of morality and their valuation of neutral mind would be positively associated with each other. It was also hypothesised (1B) that value of morality would be positively associated with valuation of significance of mind. Study 1 P6 was conducted after study 2.

In addition to the primary analyses, a set of explicit Moral Foundations measures were used to perform preliminary testing of the model's predictions for self and other-directed morality (see S5 Appendix).

\section{Method}

Participants 1425 participants undertook study 1. 150 participants undertook P1, 150 undertook P2, 250 (144 female) undertook P3, 250 (151 female) undertook P4, 375 undertook P5, and 250 undertook P6 (145 female). 100/88/119/30 participants were removed from the $\mathrm{P} 3 / \mathrm{P} 4 / \mathrm{P} 5 / \mathrm{P} 6$ data analysis based on a performance filter (see $\mathrm{S} 3$ Appendix . This resulted in a final 150 participants (86 female) for P3, 162 participants (97 female) for P4, 256 participants for P5, and 220 participants for P6 (134 female). Participants were paid 50/25/30/30/20/50 US cents for their participation in a survey, corresponding to parts $1 / 2 / 3 / 4 / 5 / 6$ respectively. This was evaluated by the participants as a significant amount of pay in all cases (rated on average 4.6 out of 5.0, with overall survey satisfaction 4.8 out of 5.0). 4/84/127/230/197 (4/56/92/162/176 final)

participants were identified as having contributed to previous parts in parts $2 / 3 / 4 / 5 / 6$ respectively.

Materials Study 1 employed a unique survey for each part (P1 to P6). The first survey (P1) consisted of 18 questions, the second (P2) of 9 questions, the third (P3) and fourth (P4) of 11 questions, the fifth (P5) of 6 questions, and the sixth (P6) of 33 questions. See S2 Appendix for a list of all survey questions and response options for the study. Survey questions in every part were of the same format; "How valuable do you consider x"; "How valuable do you consider morality", "How valuable do you consider [significance of mind measure]", "How valuable do you consider [neutral mind measure]", "How valuable do you consider [occlusion variable]", and "How valuable do you consider [dummy variable]".

The dummy variables were used to implement the performance filter (see S3 Appendix . The occlusion variables were chosen to comprise a set of pre-identified 'moral foundations' (harm, fairness, authority, loyalty, and purity; [26, 27]). This choice enabled information to be gathered with respect to their rough association with explicit morality; for future research, an effect size comparison with the variables under test, and preliminary model validation (see S5 Appendix). The surveys employed seven level Likert scales to measure strength of values, in the form of multiple choice check boxes. These ranged from "1. not very valuable" to "7. most extreme value", although the scale labels were updated slightly between parts (see S6 Appendix).

Part 6 also measured negative significance of mind ("not thinking about others"). Part 6 therefore included some additional survey questions, of the format "How bad do you consider x"; "How bad do you consider immorality", "How bad do you consider [negative significance of mind measure]","How bad do you consider [negative occlusion variable]", and "How bad do you consider [positive dummy variable]". These used the negative options " 1 . not very bad" to "7. most extreme bad".

Parts $3,4,5$, and 6 also measured political orientation. Political orientation was 
queried via an additional question ("do you consider yourself to be more liberal or more conservative") and a six level Likert scale, responses of which were used to construct a boolean measure (conservative/liberal). The political orientation question was always asked last to prevent people from defining their values with respect to their political orientation.

Parts 3, 4, and 6 also measured gender (male or female), which was provided as an optional question to accommodate sensitivities in this respect (although $99 \%$ of participants responded to this).

The order in which the variables were presented to participants were mixed between parts. Furthermore, part 5 was split into two subparts (P5a/P5b); 190 (130 final) and 185 (126 final) participants each. Items were reverse ordered in P5b (except for political orientation which was queried last), and the political orientation options were switched (conservative/liberal). Likewise, part 6 was split into two subparts (P6a/P6b). Three sets of valuation questions were reverse ordered in P6b.

Parts 1 to 6 replicated the effects for hypotheses $1 \mathrm{~A}$ and $1 \mathrm{~B}$, differing only in the selection of dummy variables, the measures used to valuate neutral mind and significance of mind, the range of the Likert scales, the ordering of the items, the number of occlusion variables tested, and the number of moderators tested. The changes between the parts are detailed in S6 Appendix.

Procedure For each part (1 to 6 ), a survey was delivered to participants as an online form (see S2 Appendix). Instructions were provided within the survey itself.

\section{Results}

For parts 1 through to 6 , the means and standard errors for the valuations of morality, the neutral mind measures (mind, sentience/consciousness, our mind/awareness, yourself/existence, mind/consciousness, and mind/sentience), and the significance of mind measures (integrity, being true to yourself and others, contemplation, conscience, and not thinking about others), are listed in Table 1.

For parts 1 to 6 , and in accordance with hypothesis $1 \mathrm{~A}$, a significant positive association was found between value of morality and value of each neutral mind measure. Likewise, in accordance with hypothesis $1 \mathrm{~B}$, a significant positive association was found between value of morality and each significance of mind measure. These correlations are listed in Table 2.

Moderators Gender and political orientation based moderation of the results from study 1 was analysed (see S7 Appendix. With respect to hypothesis $1 \mathrm{~A}$, the association between neutral mind and morality was significantly weaker for liberal males across all parts (P3, P4, and P6). With respect to hypothesis 1B, the association between morality and integrity was significantly stronger for females across all parts (P3 and P6).

Significance of mind measures Validation of the significance of mind measure integrity was performed by evaluating the definitions of integrity collated in study 3 (P1 and P2), mediation analysis of the significance of mind measures with respect to valuation of neutral mind and valuation of morality, and regression analysis (see $\mathrm{S} 4$ Appendix.

Model predictions for self and other-directed morality Moral Foundations occlusion data from study 1 (P1 to P6) were used to perform preliminary testing of the model's predictions for self and other-directed morality (see S5 Appendix. The predictions of the model for self and other-directed morality were supported. 
Table 1. Study 1 mean valuations (1: not very valuable, 7: most extreme value)

\begin{tabular}{|l|r|r|c|}
\hline & Mean & S.E. Mean & N \\
\hline Morality & & & \\
\hline part 1 (morality) & 5.83 & 0.09 & 150 \\
part 2 (morality) & 5.45 & 0.11 & 150 \\
part 3 (morality) & 5.53 & 0.12 & 150 \\
part 4 (morality) & 5.10 & 0.13 & 162 \\
part 5 (morality) & 5.47 & 0.09 & 256 \\
part 6 (morality) & 5.72 & 0.09 & 220 \\
part 6 (immorality) & 4.85 & 0.12 & 220 \\
\hline Significance of mind & & & \\
\hline part 1 (integrity) & 5.54 & 0.09 & 150 \\
part 2 (integrity) & 5.79 & 0.10 & 150 \\
part 3 (integrity) & 5.79 & 0.10 & 150 \\
part 4 (being true to self and others) & 5.78 & 0.11 & 162 \\
part 5 (integrity) & 5.77 & 0.08 & 256 \\
part 6 (integrity) & 5.98 & 0.07 & 220 \\
part 6 (contemplation) & 4.78 & 0.09 & 220 \\
part 6 (conscience) & 5.78 & 0.08 & 220 \\
part 6 (not thinking about others) & 4.28 & 0.11 & 220 \\
\hline Neutral mind & & & \\
\hline part 1 (mind) & 5.68 & 0.09 & 150 \\
part 2 (sentience/consciousness) & 5.47 & 0.11 & 150 \\
part 3 (our mind/awareness) & 5.79 & 0.10 & 150 \\
part 4 (yourself/existence) & 5.02 & 0.14 & 162 \\
part 5 (mind/consciousness) & 5.73 & 0.08 & 256 \\
part 6 (mind/sentience) & 5.59 & 0.09 & 220 \\
\hline
\end{tabular}

Table 2. Study 1 correlations with morality

\begin{tabular}{|l|r|r|r|r|}
\hline & Correlation (r) & Sig. (2-tailed) & 95\% CI min & 95\% CI max \\
\hline Significance of mind & & & & \\
\hline part 1 (integrity) & 0.46 & $<.001$ & 0.32 & 0.58 \\
part 2 (integrity) & 0.60 & $<.001$ & 0.49 & 0.69 \\
part 3 (integrity) & 0.61 & $<.001$ & 0.49 & 0.70 \\
part 4 (being true to self and others) & 0.48 & $<.001$ & 0.35 & 0.59 \\
part 5 (integrity) & 0.58 & $<.001$ & 0.49 & 0.66 \\
part 6 (integrity) & 0.47 & $<.001$ & 0.36 & 0.56 \\
part 6 (contemplation) & 0.26 & $<.001$ & 0.13 & 0.38 \\
part 6 (conscience) & 0.34 & $<.001$ & 0.22 & 0.45 \\
part 6 (not thinking about others) & 0.28 & $<.001$ & 0.15 & 0.39 \\
\hline Neutral mind & & & & \\
\hline part 1 (mind) & 0.26 & .001 & 0.10 & 0.40 \\
part 2 (sentience/consciousness) & 0.50 & $<.001$ & 0.37 & 0.61 \\
part 3 (our mind/awareness) & 0.38 & $<.001$ & 0.24 & 0.51 \\
part 4 (yourself/existence) & 0.43 & $<.001$ & 0.30 & 0.55 \\
part 5 (mind/consciousness) & 0.34 & $<.001$ & 0.23 & 0.44 \\
part 6 (mind/sentience) & 0.21 & .002 & 0.08 & 0.34 \\
\hline
\end{tabular}

\section{Discussion}

It was first (1A) hypothesised that value of morality and value of neutral mind would be positively associated with each other. This hypothesis was supported in all parts (1 to 6 ) 
of study 1, across all measures of value of neutral mind (mind, sentience/consciousness, mind/awareness, yourself/existence, mind/consciousness, and mind/sentience).

A significant gender-political orientation interaction was however observed in this association. In all parts $(3,4$, and 6$)$ of study 1 , USA liberal males tended to associate valuation of morality with valuation of mind weaker than all other groups. The difference observed for male liberals may have an environmental source, and further research is required. The extent to which this association is environmentally dependent places constraints on the capacity for valuation of mind to act as a basis for a general, unified and innate morality.

It was next (1B) hypothesised that value of morality and value of significance of mind would be positively associated with each other. This hypothesis was supported in all parts (1 to 6 ) of study 1 , and with all measures of significance of mind.

The association between perceived significance of mind and value of morality may however be dependent on gender. The association between integrity and morality was significantly lower for males than females in parts 3 and 6 (and marginally significantly lower when controlling for political orientation). This trend was replicated in part 4 (liberals only). This suggests integrity is measuring more than just significance of mind, or significance of mind is not consistently associated with morality across gender. The stronger association for females (and therefore on average) could be product of a difference in motivation between males and females in maintaining a perceived association between morality and integrity. Yet if this were merely a self-presentation bias, one would expect overall levels of integrity valuation to increase, not just its association with morality. There was no evidence of such a trend in parts 3,4 , and 6 .

\section{Study 2}

A second study (2) measured people's assignment of moral worth to a protagonist after independently manipulating their significance of mind (as expressed by scope and intensity of thought), and in both directions (positive and negative morality). With respect to hypothesis $1 \mathrm{~B}$, it was additionally hypothesised (2) that the positive and negative significance of mind manipulations would result in a significant difference in the assignment of moral worth to the protagonist.

Study 2 took a different approach to examining the relationship between significance of mind and morality (hypothesis 1B). Study 2 differed from the first study (1) in that it did not measure a general valuation of (neutral) mind, or a general valuation of significance of mind (e.g. valuation of integrity). Rather, it focused on the perception of the significance of mind of a specific human protagonist. Study 2 independently manipulated the significance of mind (valuation of specific mind) and harm foundation morality of a protagonist. This was conducted in both directions, measuring the effect of both a positive and negative manipulation, along with a neutral control condition (no manipulation). Study 2 also measured a "practical" implication of moral judgement (our perception of a protagonist's moral worth), rather than measuring association with morality directly. Likewise it measured in context and personal moral judgements (similar to study $1 \mathrm{P} 4$ ) rather than generalised, abstract moral concepts. Furthermore, the relationship between political orientation and gender and the association between significance of mind and morality was retested. Study 2 was conducted prior to study 1 P6.

\section{Method}

Participants 400 participants undertook study 2 (234 female). 139 participants were removed from the study 2 data analysis based on a performance filter (see $\mathrm{S3}$ 
Appendix). This resulted in a final 261 participants (149 female). Participants were paid 10 US cents for their participation in a survey. This was evaluated by the participants as a significant amount of pay (rated on average 4.4 out of 5.0, with overall survey satisfaction 4.7 out of 5.0). 234 (148 final) participants were identified as having contributed to previous studies (study 1 ).

Materials Study 2 employed a survey consisting of 4 questions. See S2 Appendix for a list of all survey questions and response options. Study 2 manipulated, in each direction (negative/positive), a protagonist's significance of mind ('Jasmine doesn't think much about anything'/'Jasmine thinks a lot about many things') and measured their moral worth ('How important is the moral treatment of Jasmine?'). Study 2 also included two additional conditions for effect size verification purposes; manipulating in each direction a protagonist's harm foundation morality ('Jasmine doesn't care much about anyone'/'Jasmine cares a lot about many people') and measuring their moral worth ('How important is the moral treatment of Jasmine?'). This resulted in four independent groups, along with a control condition with no manipulation applied. Study 2 used seven level Likert scales, where the options ranged from "1. not at all important" to "7. utmost importance".

Note the care/harm foundation was chosen for comparison in study 2 because there was no significant difference observed in the magnitude of the association between valuation of significance of mind (integrity) and valuation of morality, and that between valuation of care and valuation of morality (study 1 P1 to P6). Furthermore, of all the explicit foundations measured, harm was most closely associated with morality (study 1 P1 to P6). Finally, all non-harm foundation morality was found to be strongly mediated by the perception of harm, as predicted by Gray et al. 2] (study 1 P1, P2, P3, P4 and P6; see S5 Appendix.

Study 2 also measured political orientation and gender (using the same measures discussed previously).

Study 2 was split into five parts, each for a given manipulation (conditions A to E). The negative/positive signifiance of mind manipulations consisted of 103 (61 final) and 84 (56 final) participants respectively (conditions A/B). The negative/positive care manipulations consisted of 72 (44 final) and 70 (56 final) participants respectively (conditions $\mathrm{C} / \mathrm{D}$ ). The control condition consisted of 71 (44 final) participants (condition $\mathrm{E}$ ).

Procedure A survey was delivered to participants as an online form (see S2 Appendix). Instructions were provided within the survey itself.

\section{Results}

For study 2, and in accordance with the second hypothesis, a significant difference was found in the ratings of the importance of the moral treatment of protagonist Jasmine, between manipulation conditions A (thought - negative) and B (thought - positive), $t(115)=-3.23, p=.002$ (see Fig. 1).

Furthermore, no significant difference was noted in the ratings of the importance of moral treatment of protagonist Jasmine, between manipulation conditions A (thought negative) and $\mathrm{C}$ (care - negative), $t(103)=-0.60, p=.547$. Likewise, no significant difference was observed in the ratings of the importance of moral treatment of protagonist Jasmine, between manipulation conditions B (thought - positive) and D (care-positive), $t(110)=-1.17, p=.246$. 


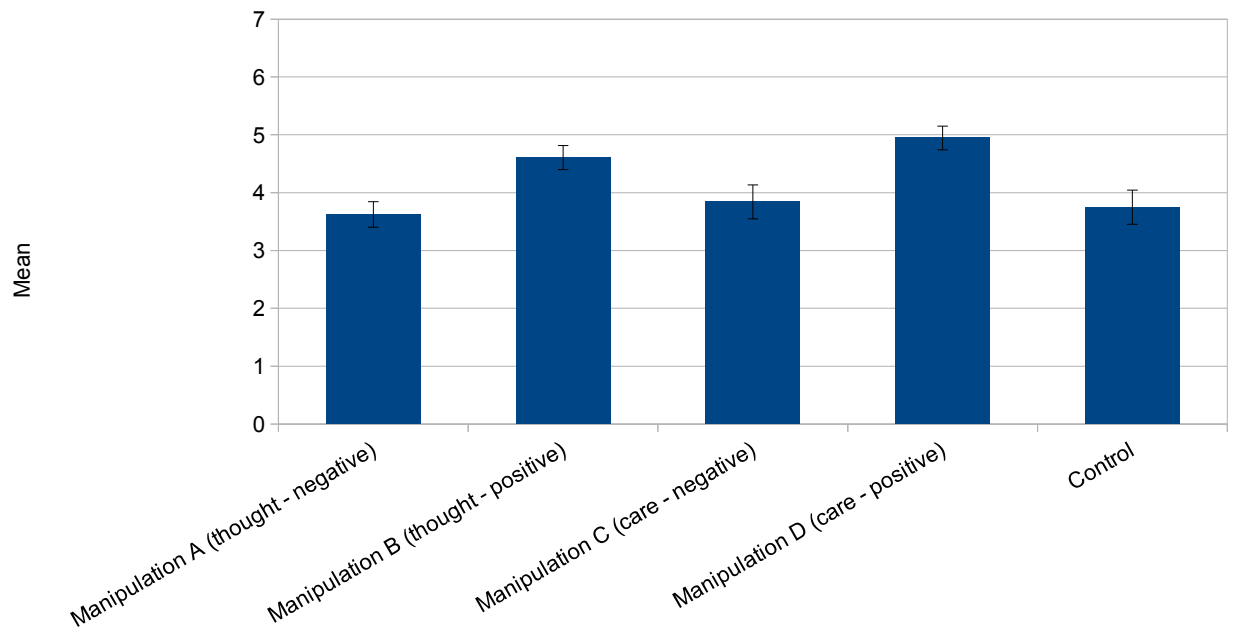

Figure 1. Study 2 mean importance ratings for the moral treatment of protagonist Jasmine. Manipulation conditions include A: thought - negative, B: thought - positive, C: care - negative, D: care - positive, and E: control. Standard errors marked. 4 corresponds to 'very important'.

Moderators With respect to hypothesis 2, no significant differences were found in gender and political orientation within the significance of mind manipulation conditions (see S7 Appendix).

\section{Discussion}

It was hypothesised (2) that the positive and negative significance of mind manipulations would result in a significant difference in the assignment of moral worth to the protagonist. Study 2 supported hypothesis 2 . There was however no difference observed between the negative manipulations and the control condition. It is possible some people automatically made assumptions about the protagonist (based purely on her name, without further details regarding her character). Future research should test multiple protagonist names, across both genders. It is also possible participants are willing to increase the importance rating for the moral treatment of someone, but are unwilling to decrease it below some minimal (perhaps even default) level.

\section{Study 3}

A third study (3) was conducted in four parts (P1 to P4). Each part asked a series of questions to determine whether people thought morality applies exclusively to (to all and only) creatures with minds. With respect to hypothesis $1 \mathrm{~A}$, it was additionally hypothesised (3) that more people would consider the application of morality relevant to all and only creatures with minds, than otherwise. Study 3 was designed to identify the dependence between mind and morality using a different method to that of studies 1 to 2 ; by asking people the kinds of creatures they apply morality to. Each part served as an important replication of the results (with the statistical analysis being based on conformance to a simple average selection point).

With respect to hypothesis $1 \mathrm{~B}$, study 3 was also designed to determine how people 
define integrity, to ensure it was not being interpreted as a synonym for morality. Study 3 (parts 1 and 2) therefore collected definitions of integrity, and verified that these contained references to integration and intrapersonal honesty (along with interpersonal honesty and moral consistency), supporting its use as a complete significance of mind measure (see S4 Appendix).

\section{Method}

Participants 500 participants undertook study 3. 135 participants undertook P1, 115 participants undertook $\mathrm{P} 2,87$ participants undertook $\mathrm{P} 3$, and 163 participants undertook $\mathrm{P} 4$. 12/16/0/13 participants were removed from $\mathrm{P} 1 / \mathrm{P} 2 / \mathrm{P} 3 / \mathrm{P} 4$ data analysis based on a performance filter (see S3 Appendix). This resulted in a final 123 participants for P1 (39 female), 99 participants for P2 (50 female), 87 participants for P3, and 150 participants for P4 (83 female). Participants were paid 20/20/10/15 US cents for their participation in a survey, corresponding to parts $\mathrm{P} 1 / \mathrm{P} 2 / \mathrm{P} 3 / \mathrm{P} 4$ respectively. This was evaluated by the participants as a significant amount of pay in all cases (rated on average 4.5 out of 5.0, with overall survey satisfaction 4.6 out of 5.0). $41 / 63 / 63 / 95$ (38/63/63/92 final) participants were identified as having contributed to previous studies or parts in parts $\mathrm{P} 1 / \mathrm{P} 2 / \mathrm{P} 3 / \mathrm{P} 4$ respectively.

Materials For study 3, the P1 survey consisted of 5 questions, the P2 survey consisted of 5 questions, the P3 survey consisted of 2 questions, and the P4 survey consisted of 5 questions. See S2 Appendix for a list of all survey questions and response options.

All parts from study 3 contained two common questions; "Morality applies to; 1 . all creatures, 2. all creatures with a mind (including humans), 3. human beings only, 4 . some human beings only" and "Do only human beings have a mind?"; "yes (human beings only)" / "no (some other creatures also)". The options were updated slightly between the parts (see S6 Appendix). Part 4 included an additional question, "Do all creatures have a mind?"; "yes" / "no".

$\mathrm{P} 1, \mathrm{P} 2$, and $\mathrm{P} 4$ also measured political orientation and gender (using the same measures discussed previously). Likewise, P1 and P2 contained the additional question, "What do you think integrity means? (in one sentence please give your opinion; without using a dictionary/encyclopedia)".

P1 consisted of 135 (123 final) participants, P2 of 115 (99 final) participants, P3 of 87 (87 final) participants, and $\mathrm{P} 4$ of 163 (150 final) participants. P1 consisted of 84 international and 51 USA participants, while P2, P3, and P4 consisted entirely of USA participants.

Parts $\mathrm{P} 1$ to $\mathrm{P} 4$ replicated the effect for hypothesis 3 , differing only in the precise wording of the questions. The changes between the parts are detailed in S6 Appendix.

Procedure For each part (P1 to P4), a survey was delivered to participants as an online form (see S2 Appendix). Instructions were provided within the survey itself.

\section{Results}

The results for study 3 are illustrated in Fig. 2 (averaged). All participant responses are recorded in Table 3

For study 3 P1, and contrary with the third hypothesis, the number of people who considered the application of morality relevant to all and only creatures with minds (43\%) was less than the number of participants who thought otherwise (57\%). In study $3 \mathrm{P} 1$, the calculated number of people who considered the application of morality 


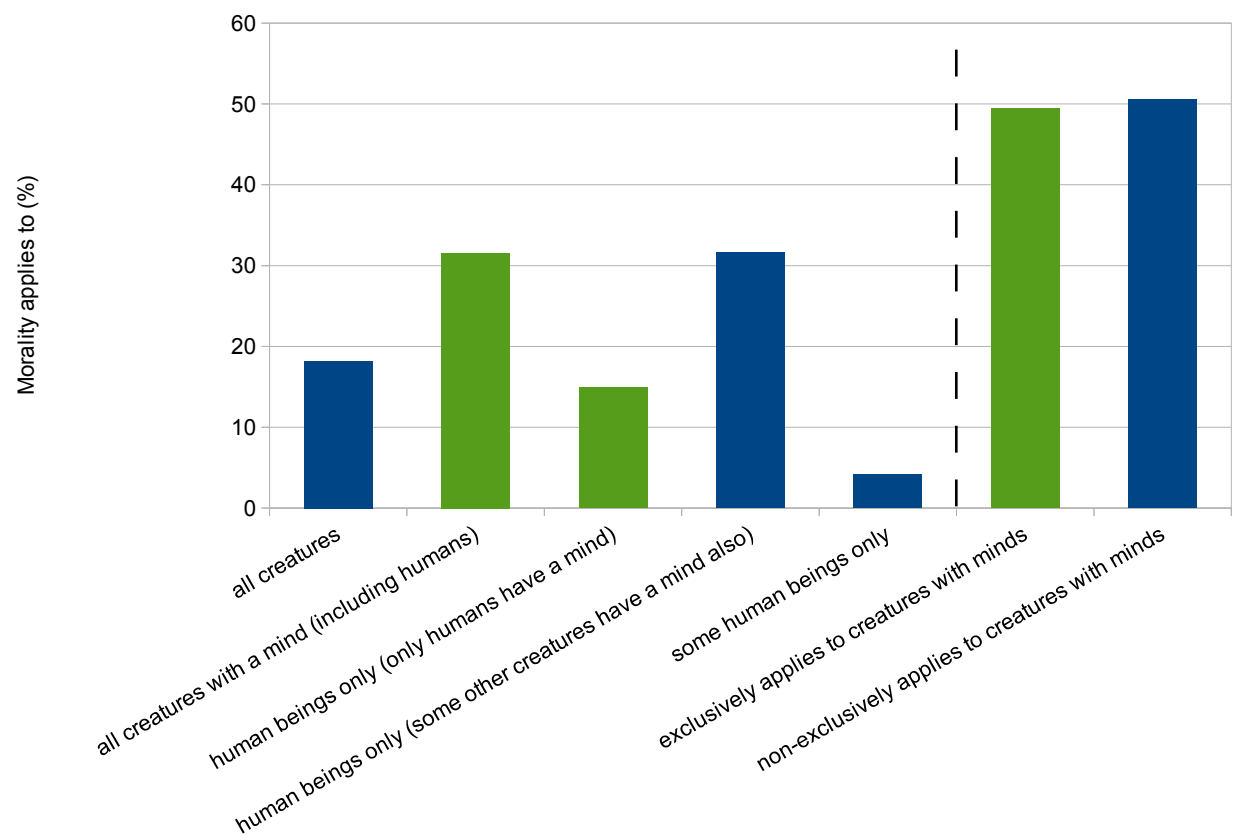

Figure 2. Study 3 participant responses on what morality applies to (averaged). Options include (a) all creatures (P4 only: [i] all creatures have a mind, [ii] not all creatures have a mind), (b) all creatures with a mind (P2/P3/P4: including humans), (c) human beings only ([i] only humans have a mind, [ii] some other creatures have a mind), and (d) some human beings only. The number of people who considered the application of morality exclusively relevant to creatures with minds was taken as (a) [i] (P4 only) + (b) + (c) [i].

Table 3. Study 3 participant responses on what morality applies to.

\begin{tabular}{|l|r|r|r|r|}
\hline Morality applies to (\%) & S3 P1 & S3 P2 & S3 P3 & S3 P4 \\
\hline all creatures & 17.89 & 13.13 & 24.14 & $(17.64)$ \\
all creatures (all creatures have a mind) & - & - & - & 13.64 \\
all creatures (not all creatures have a mind) & - & - & - & 4.00 \\
all creatures with a mind (including humans) & 21.95 & 32.32 & 37.93 & 34.00 \\
human beings only (only humans have a mind) & 21.14 & 17.17 & 12.64 & 8.67 \\
human beings only (some other creatures have a mind also) & 31.71 & 34.34 & 22.99 & 37.33 \\
some human beings only & 7.32 & 3.03 & 2.30 & 4.00 \\
\hline exclusively applies to creatures with minds & 43.09 & 49.49 & 50.57 & 54.67 \\
non-exclusively applies to creatures with minds & 56.91 & 50.51 & 49.43 & 45.33 \\
\hline
\end{tabular}

relevant to all and only creatures with minds can be considered a lower limit, as some may have interpreted option 2 of question 1 as not including human beings.

Likewise for study $3 \mathrm{P} 2$, and contrary with the third hypothesis, the number of people who considered the application of morality relevant to all and only creatures with minds (49\%) was less than the number of participants who thought otherwise (51\%). In study $3 \mathrm{P} 2$, the calculated number of people who considered the application of morality relevant to all and only creatures with minds can again be considered a lower limit, as some may have interpreted question 2 as pertaining also to supernatural 
beings (not just human beings and creatures, as per its initial context/question 1).

For study 3 P3, and in accordance with the third hypothesis, the number of people who considered the application of morality relevant to all and only creatures with minds (51\%), was greater than the number of participants who thought otherwise (49\%).

Likewise for study $3 \mathrm{P} 4$, and in support of the third hypothesis, the number of people who considered the application of morality relevant to all and only creatures with minds (55\%), was greater than the number of participants who thought otherwise (45\%).

In study $3 \mathrm{P} 1,37 \%$ of participants thought only human beings have a mind (question 2). In both P2 and P3, 28\% thought only human beings have a mind (question 2). In P4, 13\% thought only human beings have a mind (question 2), and $52 \%$ thought all creatures have a mind (question 3).

Moderators With respect to hypothesis 3, there were no significant differences found in gender and political orientation for the number of people who considered the application of morality relevant to all and only creatures with minds versus the number of people who thought otherwise (see S7 Appendix).

\section{Discussion}

It was hypothesised (3) that more people would consider the application of morality relevant to all and only creatures with minds, than otherwise. Study 3 (parts 1 to 4 ) partially supported hypothesis 3 , in that a moderately high (50\%) proportion of participants viewed morality as exclusively applying to creatures with minds. However, contrary to the hypothesis, the number of people who considered the application of morality relevant to all and only creatures with minds, was not greater than the number of people who thought otherwise. Only with the more refined measures (of exclusive application of morality to sentient creatures) implemented in P3 and P4 was the hypothesis was supported. The results indicate that there may be indirect mental dependencies involved in the attribution of moral applicability, for example the intentions of a third party. It is known that moral concern can develop around non-sentient objects, in the context of the violation of ownership rights [28].

\section{Study 4}

A fourth study (4) asked participants to rate the self-awareness and moral worth of a variety of creatures and human characters. With respect to hypotheses $1 \mathrm{~A}$ and $1 \mathrm{~B}$, it was additionally hypothesised (4) that the self-awareness and moral worth ratings of a set of creatures and human characters would be positively associated with each other.

Study 4 was designed to test the underlying theory; that people associate morality with significance of mind, and that this is associated with their valuation of neutral mind. It further tested hypothesis $1 \mathrm{~A}$ and $1 \mathrm{~B}$; whether moral worth is a measure of both the valuation of general (neutral) mind, and the valuation of specific mind (significance of mind). Study 4 (similar to study 2) differed from study 1 in that it did not only measure a valuation of (general) mind of a type of creature, but the valuation of mind of a specific human character (thereby becoming a significance of mind measure).

\section{Method}

Participants 150 participants undertook study 4. 54 participants were removed from the study 4 data analysis based on a performance filter (see S3 Appendix). This resulted in a final 96 participants. Participants were paid 30 US cents for their participation in a survey. This was evaluated by the participants as a significant amount 
of pay (rated on average 4.4 out of 5.0, with overall survey satisfaction 4.8 out of 5.0). 124 (84 final) participants were identified as having contributed to previous studies.

Materials The study 4 survey consisted of 24 questions. See S2 Appendix for a list of all survey questions and response options. Study 4 asked two questions with respect to a variety of creatures and human characters; "How important is the moral treatment of $\mathrm{x}$ " and "How much self-awareness does $\mathrm{x}$ have". It employed ten level Likert scales to measure importance of moral treatment and degree of self-awareness, in the form of a 10 point (radio button) horizontal scale. These ranged from "not important" (1) to "extremely important" (10), and "no self-awareness" (1) to "very high self-awareness" (10) respectively. Although each option (radio button) was numbered, they were only named at the extremes of the horizontal scale.

Procedure A survey was delivered to participants as an online form (see $\mathrm{S} 2$ Appendix. Instructions were provided within the survey itself.

\section{Results}

For study 4, and in accordance with the fourth hypothesis, the moral worth and self-awareness ratings for all creatures and human characters were positively associated with each other. The only exception was the human character, 'human being'. The human character, 'your mother', also exhibited a weaker correlation. The correlations for a rock are ignored here as participants were filtered based on their assignment of minimal self-awareness to a rock (see S3 Appendix). The average moral worth and self-awareness ratings for each creature and human character are shown in Fig. 3 The correlations are listed in Table 4 .

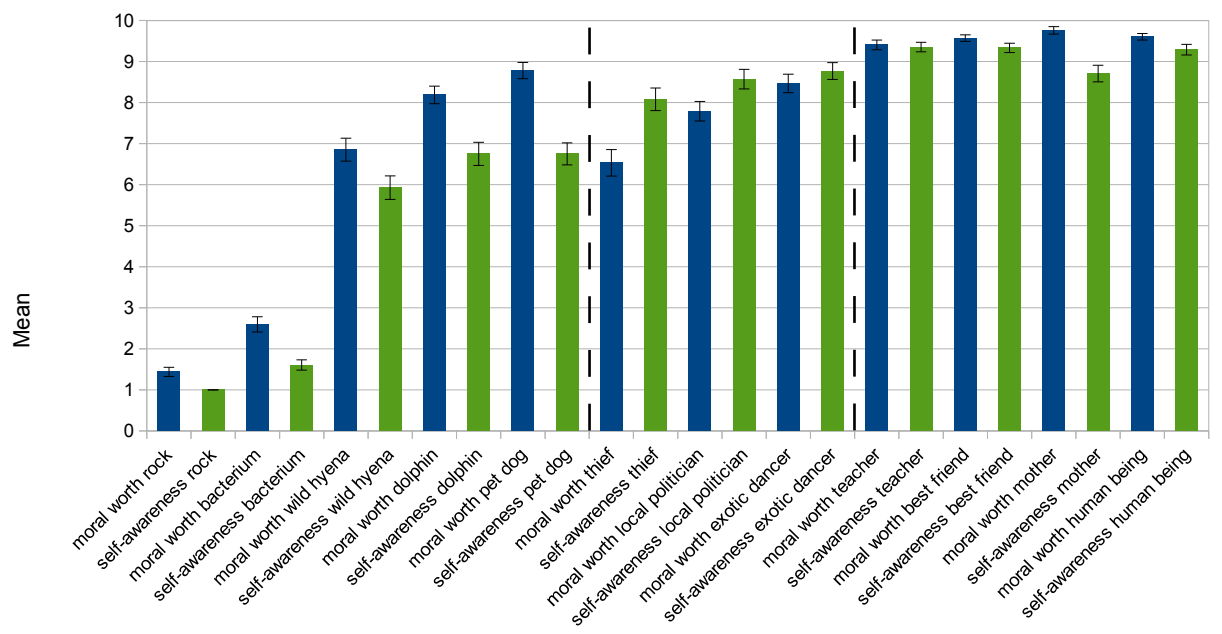

Figure 3. Study 4 mean moral worth and self-awareness ratings for all creatures and human characters. Standard errors marked. 1 corresponds to 'not important'/'no self-awareness', 10 corresponds to 'extremely important'/"very high self-awareness'. 
Table 4. Study 4 correlations between the moral worth and self-awareness ratings for all creatures and human characters.

\begin{tabular}{|l|r|r|r|r|}
\hline & Correlation (r) & Sig. (2-tailed) & 95\% CI min & 95\% CI max \\
\hline rock & - & - & - & - \\
bacterium & 0.47 & $<.001$ & 0.30 & 0.61 \\
wild hyena & 0.63 & $<.001$ & 0.50 & 0.74 \\
dolphin & 0.53 & $<.001$ & 0.37 & 0.66 \\
pet dog & 0.57 & $<.001$ & 0.41 & 0.69 \\
thief & 0.58 & $<.001$ & 0.43 & 0.70 \\
local politician & 0.57 & $<.001$ & 0.42 & 0.69 \\
exotic dancer & 0.68 & $<.001$ & 0.55 & 0.77 \\
teacher & 0.52 & $<.001$ & 0.36 & 0.65 \\
best friend & 0.50 & $<.001$ & 0.34 & 0.64 \\
mother & 0.39 & $<.001$ & 0.20 & 0.54 \\
human being & 0.18 & .078 & -0.02 & 0.37 \\
\hline
\end{tabular}

\section{Discussion}

It was hypothesised (4) that the self-awareness and moral worth ratings of a set of creatures and human characters would be positively associated with each other. Study 4 supported this hypothesis. The self-awareness and moral worth ratings were found to correlate strongly with each other for all creatures except those whose age was ambiguous ('your mother'), and the general category 'human being' (which was non-significant).

Immature human characters were purposely avoided in this study (e.g. "baby") because it was expected that these would result in high moral worth but relatively low self-awareness judgements (based on their prospective rather than current self-awareness). It is expected that the same effect occurred for the elderly character in this study (a time-independent valuation of moral worth). The low (non-significant) association observed between moral worth and self-awareness of a human being is perhaps related to the fact people have a different concept of the average moral character of a human being; moral/immoral, combined with a) the inverted self-awareness/morality relationship discussed below, and b) a ceiling effect. That is, it is possible that all participants were judging a human being as possessing high moral worth apart from subtle differences in moral character judgement (which negate the naturally positive correlation between moral worth and perceived self-awareness).

Upon close examination, it can be noted the average moral worth ratings could be predicted (modelled) based on the average self-awareness ratings using only two moderators; status as human (human/non-human), and the implicit moral character of the individual (moral/immoral). For all non-human creatures, the self-awareness ratings were found to be consistently lower with respect to their moral worth ratings, than for the human characters. Likewise, for all the immoral human characters, their self-awareness ratings were found to be consistently higher with respect to their moral worth ratings, than for the moral human characters (in fact their ratings were found to be inverted in all cases). This is consistent with the underlying theory, that morality is associated with both valuation of specific mind (significance of mind of particular human characters) and valuation of general mind (the sentience of a particular type of creature). This research independently suggests there are two factors determining the application of a being to a moral judgement circle; as suggested by both Haslam 22] and Gray et al. [2]. These constructs are however considered separable [29], and neither directly map to neutral mind and significance of mind. Further work is required to reconcile their origin. 


\section{Study 5}

A fifth study (5) asked participants to rate the moral worth of either a human being, philosophical zombie, or 'philosophical phantom', along with that of a rock. A philosophical zombie is a hypothetical non-sentient creature that is physically identical to a conscious healthy human being [30, and a philosophical phantom is a hypothetical sentient inanimate object. It was expected that the valuation of neutral mind manipulations (existential nature) would result in a significant difference in the perceived moral worth of the creature. With respect to hypothesis $1 \mathrm{~A}$, it was additionally hypothesised (5A) that the moral worth ratings of a human being would be significantly greater than the moral worth ratings of a philosophical zombie. Likewise, it was hypothesised (5B) that the moral worth ratings of a philosophical phantom would be significantly greater than the moral worth ratings of a rock.

Study 5 was designed to further test the underlying theory, with respect to its specific claim regarding the importance of the evaluation of the existential nature of mind in the context of morality. It further tested hypothesis 1A; that morality (moral worth) is associated with valuation of neutral mind (its existential nature).

\section{Method}

Participants 200 participants undertook study 5. 46 participants were removed from the study 5 data analysis based on a performance filter (see S3 Appendix). This resulted in a final 154 participants. Participants were paid 15 US cents for their participation in a survey. This was evaluated by the participants as a significant amount of pay (rated on average 4.8 out of 5.0, with overall survey satisfaction 4.9 out of 5.0). 148 (121 final) participants were identified as having contributed to previous studies.

Materials Study 5 was conducted in 3 parts (A, B, C). The survey used in part B consisted of 2 questions, and the surveys used in parts A and $\mathrm{C}$ consisted of 3 questions. See S2 Appendix for a list of all survey questions and response options. Study 5 asked two questions, with respect to (i) either a philosophical zombie (part A), human being (part B), or philosophical phantom (part C), and (ii) a rock; "What is the moral worth of x". Study 5 employed ten level Likert scales to measure moral worth, in the form of a 10 point (radio button) horizontal scale. This ranged from "not valuable" (1) to "extremely valuable" (10). Although each option (radio button) was numbered, they were only named at the extremes of the horizontal scale. Study 5 parts A and C also included a third question (manipulation check); "What is a philosophical zombie/phantom (according to the introduction)?" Question 2 of study 5 part C was also changed to "What is the moral worth of a rock (not a phantom)", to ensure the participants knew that it was not referring to the example philosophical phantom given in the introduction.

A philosophical zombie (manipulation A) was described as a hypothetical creature which is physically identical to a human being but has no internal mental reality. It looks the same as a human being, relates the same, and talks the same as a human being. Its brain and body function perfectly according to the laws of physics. A philosophical zombie's brain processes colour, movement, noise, and emotion information, but it does not see, hear, or feel anything. It appears to be conscious and sentient but it is not.

A philosophical phantom (manipulation C) was described as a hypothetical creature which is physically identical to an inanimate object but has an internal mental reality. It might look the same as a rock, relate the same, move the same. Its matter functions perfectly according to the laws of physics. A philosophical phantom's matter does not process colour, movement, noise, and emotion information, but it sees, hears, and feels things. It doesn't appear to be conscious and sentient but it is. 
A human being was not described (manipulation B).

Part A consisted of 100 (77 final) participants, part B of 50 (43 final) participants, and part $\mathrm{C}$ of 50 (34 final) participants.

Procedure A survey was delivered to participants as an online form (see S2 Appendix . Instructions were provided within the survey itself.

\section{Results}

For study 5, and in accordance with the fifth hypothesis, the valuation of mind manipulations (existential nature) resulted in a significant difference in the perceived moral worth of a creature. See Fig. 4 .

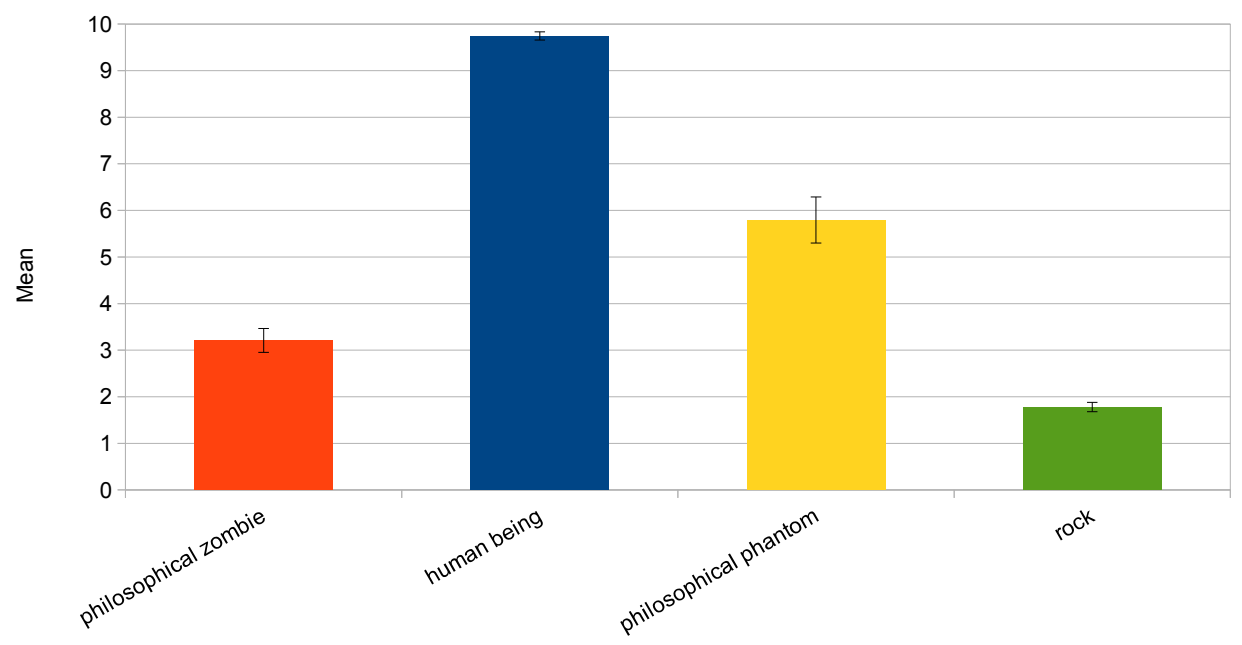

Figure 4. Study 5 mean moral worth ratings for a philosophical zombie, human being, philosophical phantom, and rock. Standard errors marked. 1 corresponds to 'not valuable', 10 corresponds to 'extremely valuable'.

In accordance with hypothesis $5 \mathrm{~A}$, a significant difference was found in the ratings of the moral worth of a philosophical zombie and that of a human being, $t(92.8)=-24.10$, $p<.001$. Furthermore, nearly everyone rated a human being as possessing greater moral worth than a philosophical zombie (see Fig. 5). It was also noted that the moral worth ratings of a philosophical zombie were significantly closer to those of a rock than those of a human being, $t(71.0)=-7.64, p<.001$.

Likewise, in accordance with hypothesis $5 \mathrm{~B}$, a significant difference was found in the ratings of the moral worth of a philosophical phantom and that of a rock, $t(33)=6.91$, $p<.001$. It was also noted that the moral worth ratings of a philosophical phantom were significantly greater than those of a philosophical zombie, $t(109)=-5.10, p<.001$.

The rock moral worth evaluations in the philosophical phantom $(\mathrm{C})$ condition $(M=2.62)$ were however significantly higher than those in the philosophical zombie (A) condition $(M=1.60), t(46.9)=-3.44, p=.001$, making a direct comparison between conditions $\mathrm{A}$ and $\mathrm{C}$ difficult. Yet given that the difference between rock moral worth evaluations in the philosophical phantom and philosophical zombie conditions $(M=2.62-1.60=1.02)$ was significantly less than the difference between the philosophical phantom and philosophical zombie moral worth evaluations $(M=5.79-3.21=2.58)$, 


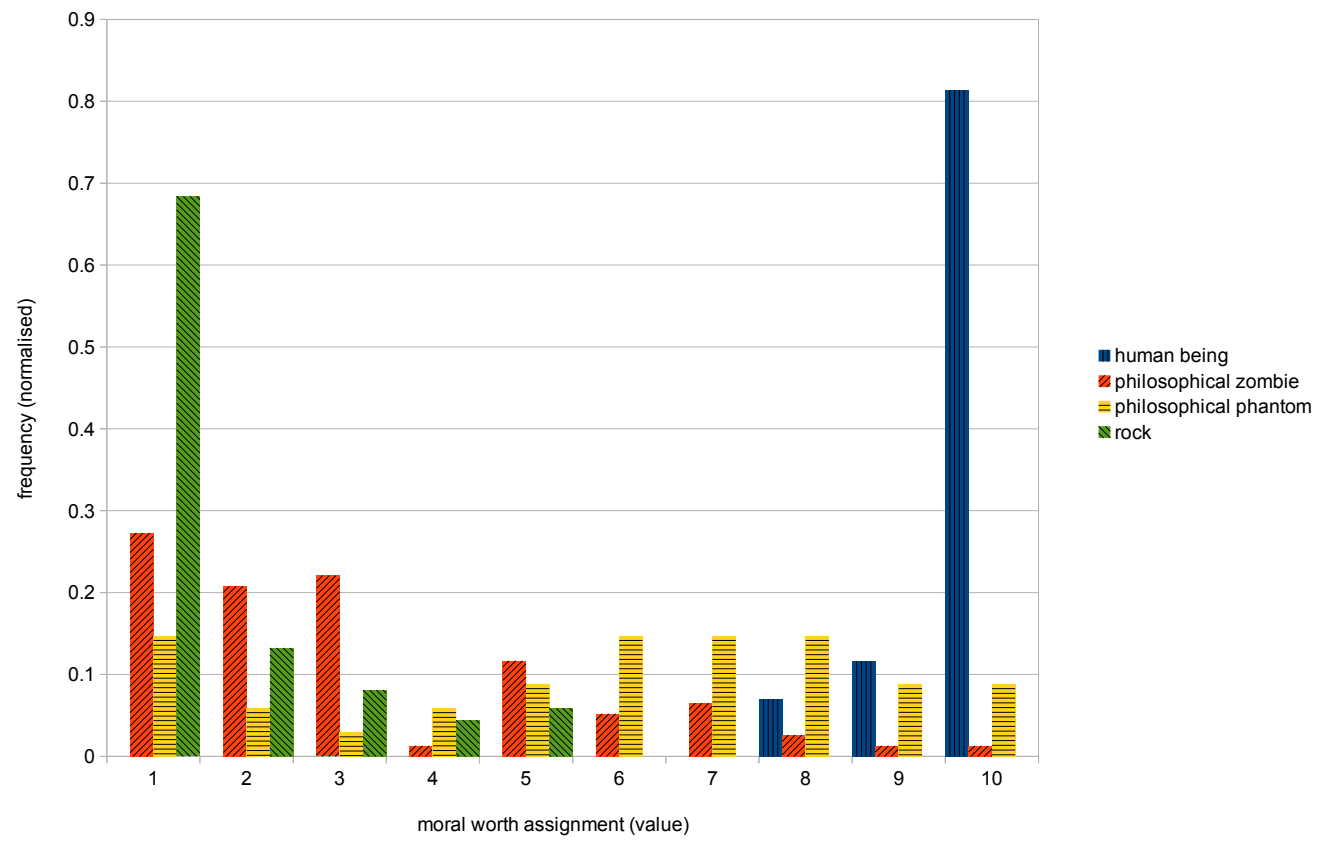

Figure 5. Study 5 histograms of the moral worth ratings of a philosophical zombie, human being, philosophical phantom, and rock. 1 corresponds to 'not valuable', 10 corresponds to 'extremely valuable'.

$t(53.6)=2.06, p=.045$, it can be inferred that the above observation is robust (the moral worth ratings of a philosophical phantom were significantly greater than those of a philosophical zombie).

\section{Discussion}

It was expected that the valuation of neutral mind manipulations (existential nature) would result in a significant difference in the perceived moral worth of a creature. Study 5 supported hypothesis 5 . In accordance with hypothesis $5 \mathrm{~A}$, the moral worth ratings of a human being were significantly greater than the moral worth ratings of a philosophical zombie. Furthermore, it was noted that the moral worth ratings of a philosophical zombie were significantly closer to those of a rock than those of a human being. Likewise, in accordance with hypothesis $5 \mathrm{~B}$, the moral worth ratings of a 'philosophical phantom' (a sentient inanimate object) were significantly greater than that of a rock. Moreover, it was noted that the moral worth ratings of a philosophical phantom were significantly greater than those of a philosophical zombie.

\section{General Discussion}

These studies aimed to determine if people's valuation of morality was associated with their valuation of mind, and perceived significance of mind. In support of the first hypothesis $(1 \mathrm{~A})$, a significant positive association was confirmed between value of morality and all measures of value of neutral mind, across all parts (study 1; P1 to P6). In support of the first hypothesis (1B), a significant positive association was confirmed 
between value of morality and the significance of mind measures (integrity, being true to yourself and others, contemplation, conscience, and not thinking about others). In support of the second hypothesis, it was found that the significance of mind manipulations of the protagonist resulted in a significant difference in the assignment of moral worth to the protagonist (study 2). In partial support of the third hypothesis, $50 \%$ of participants thought morality applies exclusively to creatures with a mind (averaged across all parts of study 3). In support of the fourth hypothesis, the self-awareness and moral worth ratings of all creatures and human characters were highly correlated (except for those whose age or moral character was ambiguous; study 4). In support of the fifth hypothesis, the moral worth ratings of a human being were significantly greater than the moral worth ratings of a philosophical zombie. Likewise, in support of the fifth hypothesis, the moral worth ratings of a 'philosophical phantom' (a sentient inanimate object) were significantly greater than those of a rock (study 5).

With respect to hypothesis $1 \mathrm{~A}$, it was seen that morality was consistently associated with valuation of neutral mind for all participants except liberal males, across all parts of study 1 (P1 to P6).

With respect to hypothesis $1 \mathrm{~B}$, there was a strong association between integrity and morality irrespective of political orientation, although gender differences were apparent (females valuing it more so than males).

In further support of the underlying theory, studies $2,3,4$, and 5 suggest moral worth judgements are highly dependent on perceived scope and intensity of thought (specific mind/significance of mind), perceived presence of mind, perceived self-awareness (both valuation of specific mind/significance of mind and valuation of general mind), and perceived existential nature of mind (valuation of general mind). They differed from study 1 in that they did not measure a general valuation of significance of mind (a quality which any specific mind holds to varying degrees), or a general valuation of neutral mind.

Study 2 manipulated the perception of the significance of mind of a specific protagonist (valuation of specific mind), and asked participants to rate her moral worth. Study 2 supported the underlying theory, in that the significance of mind (scope and intensity of thought) manipulations affected the moral worth judgements (to a similar degree as the care manipulations in this sample).

Study 3 asked participants what kinds of creatures morality is relevant to. Similarly, in accordance with the theory, study 3 suggests a moderately strong dependence on mind in the attribution of morality to a creature.

Likewise, study 4 measured the valuation of mind (degree of self-awareness) of a set of general creatures and specific human characters (in this case becoming a significance of mind measure). Study 4 supported the underlying theory; that morality is a consequence of the significance of mind. Valuation of morality is associated with the valuation of significance of mind, and this is associated with the valuation of neutral mind.

Finally, study 5 manipulated the perception of the existential nature of mind (value of general mind) of a human being or rock, and asked participants to rate its moral worth. Study 5 supported the underlying theory, in that the valuation of general mind (existential nature) manipulations affected the moral worth judgements. Moreover, the moral worth ratings of a philosophical zombie were significantly closer to those of a rock than those of a human being, and the moral worth ratings of a philosophical phantom were significantly greater than those of a philosophical zombie.

\section{Limitations}

Future research should compare the significance of mind constructs used herein, and conduct a comprehensive construct validity. 
The association between valuation of morality and neutral mind was lower for liberal males, and the association between integrity and morality was lower for males. The environmental dependence of the associations constrain the capacity for mind to represent the basis of an innate and unified moral system. It is possible however that these simply highlight interpersonal/intergroup variations in morality (with respect to a common ideal).

Likewise, the testing of the model's predictions for self and other-directed morality must be extended. Some people may not have interpreted purity in a moral context (despite the contents of the survey); exacerbating its discrepancy with respect to the care foundation.

Future research must also examine not only the positive association between positive values (virtues) and moral value, but the negative association between negative values (vices) and moral value. Studies 1 (part 6) and 2 provided tentative evidence that the significance of mind construct (along with the care foundation) may be differentially active in both negative and positive moral judgement.

Furthermore, not everyone exclusively attributed morality to creatures with minds (study 3). Future research should investigate the possibility of indirect mental dependencies in the attribution of moral applicability (i.e. not only the mind of the agent or patient, but the intentions of a third party).

The results here could also have been inadvertently affected by participants. In order to reduce self-presentation bias, implicit association tests could be employed in measuring people's concept of morality. Implicit association tests were not used in these studies because of evidence these may measure socialised categories rather than attitudes or values [31].

Despite prospects of their significant association, limitations remain also for the application of research into morality and mind. Lagattuta and Weller [5] highlight the deficiency of reasoning/reporting about scenarios concerning moral action versus measuring moral behaviour itself.

\section{Implications}

This research highlights the relevance of theory of mind in moral valuation. There appears to be opportunity available to measure interactions between morality and our innate versus socialised, implicit versus explicit theory of mind.

Likewise, this research suggests morality is based on the belief in mind. In this respect morality might be considered a fundamentally rational process.

Moreover, study 5 indicates that morality is critically dependent on the perception and valuation of neutral mind (sentience). It directly manipulated the perception of existential mind (mental properties). Unlike what has been emphasised in H. Gray et al. [1] and Gray et al. [2], it suggests that the two dimensions of mind perception are not independent; that moral patiency and moral agency are not mutually exclusive.

Again, contrary to Gray et al. [2], preliminary analysis supported the prediction of self and other-directed morality. Morality may not be a necessarily dyadic process.

Further research is required to determine the precise extent to which moral valuations are dependent on innate intuition (such as adaptive emotion) and reason (such as a logical conclusion and therefore byproduct of an evolved belief in mind as here argued). Morality could be better seen as hierarchical rather than modularised; based on adaptations, metacognitive artefacts, and the environment.

Similarly, this work has implications for the nature of morale, in that it too may be dependent on belief in the significance of mind. It might explain self-sacrifice with respect to the body (e.g. [32]), including the suppression of physical desire.

Furthermore, a framework is offered for understanding human culture in general, including the arts. Concerning anthropology, it suggests religious sacrifice may have a 
natural ground; the assertion of significance of mind via the free willed subjugation of nature. Likewise, the elevation of the supernatural (e.g. magic/gods/animism/etc.) might heighten the importance of the mind, vindicating their belief.

Finally, this research has broader implications for cognition and artificial intelligence. It suggests that the agent constrains its own behaviour (morality) based on a belief in the non-observable nature of mind.

\section{Conclusion}

These studies uncovered a positive association between people's valuation of morality and both their valuation of general mind and their valuation of specific mind (significance of mind). Moreover, they found moral worth judgements to be strongly affected by the manipulation of both perceived significance of mind and perceived existential nature of mind. Likewise, they found a moderate dependence on mind in the perception of moral relevance, and a strong association between perceived self-awareness and moral worth judgements. This research attempted to formulate a general basis for morality, and paralleling H. Gray et al. [1], it has identified a candidate for further investigation; the valuation of mind. It suggests however that morality is crucially based on the belief in sentience (existential mind; mental properties). Preliminary analysis supported also its prediction of self and other-directed morality. Future work is needed to comprehensively address moral valuation.

\section{Supporting Information}

\section{S1 Appendix}

\section{Theoretical Bases}

\section{S2 Appendix}

\section{Surveys}

\section{S3 Appendix}

Bad data filtering

\section{S4 Appendix}

Significance of mind measures

\section{S5 Appendix}

Model predictions for self and other-directed morality

\section{S6 Appendix}

\section{Changes between studies}

\section{S7 Appendix}

\section{Moderators}




\section{References}

1. H Gray HM, Gray K, Wegner DM. Dimensions of mind perception. Science. 2007;315(5812):619-619.

2. Gray K, Young L, Waytz A. Mind perception is the essence of morality. Psychological Inquiry. 2012;23(2):101-124.

3. Cameron J. Terminator 2: Judgment Day: Extended Special Edition. TriStar Pictures; 2000.

4. Haidt J. The emotional dog and its rational tail: A social intuitionist approach to moral judgment. Psychological review. 2001 Oct;108(4):814-834.

5. Lagattuta K, Weller D. Interrelations between theory of mind and morality: A developmental perspective. In: Handbook of moral development. 2nd ed. Psychology Press; 2014. p. 385-407.

6. Malti T, Ongley SF. The development of moral emotions and moral reasoning. In: Handbook of moral development. vol. 2. Psychology Press New York; 2014. .

7. Haidt J. The emotional dog and its rational tail: a social intuitionist approach to moral judgment. Psychological review. 2001;108(4):814.

8. Suhler CL, Churchland P. Can innate, modular "foundations" explain morality? Challenges for Haidt's moral foundations theory. Journal of cognitive neuroscience. 2011;23(9):2103-2116.

9. Barclay P, Van Vugt M. The Evolutionary Psychology of Human Pro-sociality: Adaptations, Byproducts, and Mistakes. In: Schroeder D, Graziano W, editors. Oxford Handbook of Prosocial Behavior (Forthcoming). Oxford University Press; 2014. .

10. Rai TS, Fiske AP. Moral psychology is relationship regulation: moral motives for unity, hierarchy, equality, and proportionality. Psychological review. 2011;118(1):57.

11. Barrett HC, Bolyanatz A, Crittenden AN, Fessler DM, Fitzpatrick S, Gurven M, et al. Small-scale societies exhibit fundamental variation in the role of intentions in moral judgment. Proceedings of the National Academy of Sciences. 2016;113(17):4688-4693.

12. Baumeister RF, Smart L, Boden JM. Relation of threatened egotism to violence and aggression: the dark side of high self-esteem. Psychological review. 1996;103(1):5.

13. Bloom P. Religion is natural. Developmental science. 2007;10(1):147-151.

14. Keysers C, Kaas JH, Gazzola V. Somatosensation in social perception. Nature Reviews Neuroscience. 2010;11(6):417-428.

15. Avenanti A, Minio-Paluello I, Bufalari I, Aglioti SM. The pain of a model in the personality of an onlooker: influence of state-reactivity and personality traits on embodied empathy for pain. Neuroimage. 2009;44(1):275-283.

16. Singer P. Animal Liberation. Pimlico; 1975. 
17. Chalmers D. Panpsychism and Panprotopsychism. In: Alter T, Nagasawa Y, editors. Consciousness in the Physical World: Perspectives on Russellian Monism. Oxford University Press; 2015. p. 246-276.

18. Flavell JH. Metacognition and cognitive monitoring: A new area of cognitive-developmental inquiry. American psychologist. 1979;34(10):906.

19. Plato. The dialogues of Plato. 360BC;

20. Aristotle. Nicomachean Ethics. 350BC;.

21. Boethius. The Consolation of Philosophy. 520AD;.

22. Haslam N. Dehumanization: An integrative review. Personality and social psychology review. 2006;10(3):252-264.

23. Dennett DC. Kinds of minds: Toward an understanding of consciousness. Basic Books; 1997.

24. Gray K, Wegner DM. Moral typecasting: divergent perceptions of moral agents and moral patients. Journal of personality and social psychology. 2009;96(3):505.

25. Graham J, Haidt J, Nosek BA. Liberals and conservatives rely on different sets of moral foundations. Journal of Personality and Social Psychology. 2009;96(5):1029-1046.

26. Haidt J, Joseph C. Intuitive ethics: How innately prepared intuitions generate culturally variable virtues. Daedalus. 2004;133(4):55-66.

27. Haidt J, Graham J. When morality opposes justice: Conservatives have moral intuitions that liberals may not recognize. Social Justice Research. 2007;20(1):98-116.

28. Millar JC, Turri J, Friedman O. For the Greater Goods? Ownership Rights and Utilitarian Moral Judgment. Cognition. 2014;133:79-84.

29. Haslam N, Loughnan S, Holland E. The psychology of humanness. In: Objectification and (De) humanization. Springer; 2013. p. 25-51.

30. Kirk R, Squires R. Zombies v. materialists. Proceedings of the Aristotelian Society, Supplementary Volumes. 1974;p. 135-163.

31. Karpinski A, Hilton JL. Attitudes and the Implicit Association Test. Journal of personality and social psychology. 2001;81(5):774.

32. Sachdeva S, Iliev R, Ekhtiari H, Dehghani M. The Role of Self-Sacrifice in Moral Dilemmas. PloS one. 2015;10(6):1-12. 


\section{S1 Appendix - Theoretical Bases}

\section{Existing theory of mind research}

Work suggests that moral emotions may mediate the link between moral standards and behaviour [1]. By the age of five, negative emotions triggered through violations by self (e.g. guilt/shame) predict moral behaviour [2]. It is argued negative emotions make the person aware of the moral relevance of a situation (by bringing discomfort), and can therefore function as a precursor to moral judgement. Yet such emotions become increasingly tied to an understanding of both moral judgement and the feelings of others 3, 4]. Cognitive neuroscience suggests emotions with regards to another's mental state (e.g. compassion, admiration of virtue) can encourage reflective introspection; the conscious evaluation of affect [5. Likewise, it has been suggested that a precondition for prosociality in children is an understanding of the desires and needs of others in relation to their own [6].

Developmental studies find moral judgement to have both an affective and cognitive component [7, 8. Moral emotions and cognition are both important in the habituation of moral action [9], and the restriction of aggressive immoral behaviour [10]. Similarly, cognitive neuroscience suggests moral judgements involve both affect and reasoning [11, 12. Empathy has been found to have both an affective (emotional) and cognitive component [13]. Affective empathy relies on emotional systems (e.g. insula, amygdala), where as cognitive empathy relies on theory of mind processing (prefrontal and outer temporal cortex; 14]). Moreover, the brain has neural networks (mirror neurons) dedicated to the experience of action and thought of others, supporting cognitive empathy [15]. Although phylogenetically distinct [16], these facilitate experience of another's feelings [17, 18, for example pain [19, 20]. Accordingly, perspective taking can facilitate affective empathy [21. Likewise, some research suggests that moral decisions might invoke brain regions involving theory of mind to a greater extent than those involving affective empathy [22].

Theory of mind is the capacity to attribute mental states to oneself and others [23, and is a form of metacognition, or thinking about thinking [24]. Research has begun to test theory of mind in the context of moral psychology (see [25] for a review). Theory of mind has been linked to the ability to identify intention in moral acts [26, 27]. Likewise, there has been some support in the developmental literature that theory of mind can facilitate fairness [28]. There is also evidence of an effect in the opposite direction; theory of mind is partially determined by one's experience of another's moral judgements [29]. Theory of mind research to date does not however examine people's evaluation of their theory of mind in the context of moral judgement.

\section{Existing theories of descriptive morality}

Traditional psychological models of moral judgement are based on deliberative reasoning and rationality [30]. Pure socio-cognitive accounts do not however provide a strong evolutionary grounding to cross-cultural morality. Thus, contemporary models have been developed around the activation (or co-option) of adaptive unconscious systems [31 33. Such intuitionist accounts argue that moral reasoning is primarily a posthoc artefact of unconscious moral judgement, with moral judgement itself being based on arational emotion.

The best evidence at present for a modular intuitionist model of morality is the specificity of emotion to particular moral foundations [34, 35. It is unlikely such emotional responses could be socialised cross-culturally. Some research suggests that disgust and anger may however generalise to multiple moral foundations [36, 37]. Moreover, these emotions might be better construed as pertaining to immorality rather 
than morality. Sexual desire (degradation) likely evolved to overcome disgust, aggression (harm) likely evolved as a response to anger (personal threats), and evening the odds (subversion, cheating, and betrayal) likely evolved as a response to contempt (threats by peers within the community). Their association with morality could simply be an artefact of adaptive immorality. Modular intuitionist accounts have also been criticised based on a purported weak theoretical basis [38. There exist little analogies at present to how five (or more) independent systems could evolve to facilitate morality, be encoded in the brain, and converge to produce a single cognitive response.

Furthermore, morality often competes against systems more directly benefiting one's genes; such as copulation with an available physically fit (or dominant) mate. The current moral psychology literature however appears to focus on measuring (perceived) moral judgements versus explicit moral ideals or values. These moral judgements are often made with respect to a third party (whether artificial as in moral dilemmas, or concrete as in judgement of contemporary social issues) rather than oneself. The ethical opportunities to manipulate immoral behaviour are limited. They often regard the judgement of or opportunity to perform some moral act under pretense of a reward (standard participant payment), rather than invoking situations in which a moral decision involves the active negation of a primitive desire to do otherwise (a decidedly immoral act; such as murder or sexual violence). In such scenarios the evaluation of mind may play a greater role.

Likewise, there exists considerable debate concerning the extent to which moral intuition and deliberation play a role in moral judgement [39]. The signature moral response (40, 41]; wrong/serious, punishable, authority independent, general in scope) could be both a logical conclusion of belief in mind, and a consequence of it being threatened. Our intuitions/emotions may develop to support the signature moral response, but are not necessarily its basis. Contrary to intuitionist and hybrid models [42], such morality could ultimately be a product of System 2, cognitive resource heavy processes. We might develop and socially co-opt emotional systems to facilitate the learning of these moral requirements (resulting in intuitive moral reactions such as disgust when these beliefs are threatened). This suggests cross-cultural morality could be a learnt association based on an underlying principle or pre-existing belief.

Various evolutionary byproduct models have been proposed. Some are based on the cultural establishment of sentimental norms assuming their common evaluation under idealised conditions [43]. Others have viewed morality as a byproduct of cognitive abilities specific to intelligent creatures; the anticipation of behavioural consequences and the evaluation of alternatives [44, 45]. Still others have proposed that morality could be a byproduct of adaptations related to general tolerance or conformist transmission [15. It is not clear that such account for the seriousness of moral judgements however. Alternatively, it has been proposed that (cognitive) empathy itself-and therefore its moral consequences-might be a byproduct of the adaptiveness of both imitating others (the development of mirror neurons) and theory of mind. Supporting this position, it has been suggested that theory of mind may be dependent on simulation circuits [46. Morality might therefore be a byproduct of an evolved belief in valuable not-only-physical mind and the logical projection of this belief to like others.

\section{Distinguishing morality from amorality (motivation)}

Morality concerns both the positive (moral or 'good') and negative (immoral; for example 'self-centred' or 'evil'). Likewise amorality is both positive ('good') and negative ('bad'). Positive and negative morality are commonly framed in terms of prescriptive and proscriptive prerogatives, but this does not mean the satisfaction of (these) rules determine the morality of an action or inaction. Prosocial (caring) behaviours are for example often unconscious [47. 
Accordingly, some have proposed that morality is determined by the perceived motive of the act 48. Likewise, evidence suggests that intent perception is a cross-cultural determinant of moral judgements [49]. The mitigating factor of 'necessity' (doing harm to help another) exhibited universal applicability in the severity of moral judgements (across nine societies).

One such possible motivation for positive moral action is whether it is done based on belief in mind (its significance) or not. This concords with the position that morality without empathy is oxymoronic [50. From such a perspective, prosocial behaviour done out of selfish motive is considered either amoral (irrelevant to morality) or immoral (if done without sufficient respect for another person). Likewise, prosocial behaviour if meant (intended) to ultimately hurt another person is seen as immoral (such as being nice to someone to make them feel bad for hurting them for some unrelated transgression-out of revenge).

Note this model supports both deontological and utilitarian judgement to the extent that they are made with respect to the internal worth of an individual or individuals. Yet evidence of a possible association between utilitarianism and psychopathic traits [51] further supports the need to investigate the relationship between morality and motivation. It has for example been argued in the philosophical literature that the good is not in the end, it is in the means [52].

Negative morality (immorality) is also tied to morality, and is not necessarily a simple absence of morality. It is known that prosocial behaviour is dependent on identity, not only emotions and reason [53. Likewise it is closely tied to our sense of self, in that threats to self can reduce unethical behaviour [54]. Yet threats to self can also enhance unethical behaviour (e.g. revenge; [55]).

Moral theory must be able to account for the fact prosocial behaviour does not of itself imply morality, and morality depends on the motivation behind the act being performed. A candidate motive for the classification of morality is whether it is performed based on the importance of one's mind and that of others (theory of mind). Likewise, moral theory must be able to account for the fact many negative moral behaviours often drive from similar motivations to positive moral behaviours, and are not necessarily a simple absence of morality (amorality).

\section{Consequences of the evolutionary development of an internal representation of self}

The creature has developed a model of itself as a sentient being from the survival benefits it once brought (and arguably still brings), particularly as a social mammal. Our species cannot deny its existence being evolutionarily programmed that way. (It can also be argued philosophically, from the anthropic principle, that we could not exist in/mapped to any other physical construct; one without a strong belief in or conviction in ourselves as an observer; as our universe has been selected for this; the evolution of a creature that can knowingly observe it). The projection of mind to others if innate could likewise have evolved to enhance the group's survival in conflict, and to share social bonds. Both emotions like affective empathy and the reliable development of theory of mind in children suggest an innate component to theory of mind (at least at an implicit or purely functional capacity).

Many theory of mind researchers assume self-directed theory of mind develops through mind-reading; the formation of second-order beliefs regarding others 24. Yet others argue that cognitive empathy is a byproduct of self-awareness [56. Here a similar perspective is taken, in that explicit other-directed theory of mind is viewed primarily as a rational (logical) extension of the central belief (the existence of one's own mind). Such is enabled based on social learning and systems supporting the development of the 
belief (capacity for affective empathy, second order beliefs, etc). In this respect the theory of morality proposed (the projection of valuable mind) conforms to historic models; being viewed as a product of intellect and deliberative reasoning.

Most research (e.g. [57]) discusses belief in mind in the context of the apparent natural development of substance (Cartesian) dualism, yet this fails to capture beliefs in a mental reality independent of one's philosophy of mind. Under the current materialist paradigm, these are viewed as emergent mental properties (or whichever terminology is preferred here to retain some form of physicalism without eliminativism). Discovering a representation of mind in the brain (the evidence based development of physicalism) is an extremely modern accomplishment(/enterprise), and the effect of the development of contemporary philosophy of mind on our perception of the mind is unestablished (there could be no difference in our evaluation of mind in terms of its demand for moral worth; its significance).

The implications of our belief concerning the nature and significance of mind have seen even less attention in the literature. Some studies link compatibilist and incompatibilist free will models to moral behaviour (e.g. [58, 59]), although none here study the implications of folk philosophy of mind with respect to the belief and value of mind itself (irrespective of its dependency on or otherwise independence from the material world). There is however much related research existent in the literature concerning the negation of belief in mind (e.g. 60, 61; dehumanisation, discussed below).

\section{The coevolution of extra-group morality and our discovery of a common humanity}

It is possible that historic variations in moral assignment are a consequence of the varying projection of this belief in mind to other groups (cultures, races, and perhaps even gender and age groups; e.g. [62]). The reason for such variation in the projection of mind (as suggested) could simply be a lack of education or knowledge concerning another's capacity to be like oneself (or one's group; as seen for example in Aristotelian philosophy with regards to alternate gender and race [52], although it is likely coupled with a bias to dehumanise or fail to humanise those when it is genetically beneficial to do so). As such, it is feasible that human culture in general including the tendency to accept systems of morality is consequent (byproduct) of this evolved belief.

Furthermore, it is unlikely that civilisation has developed stable moral systems based on biased moral mechanisms ('moral adaptations'; evolutionary or otherwise). For if such were to be demonstrated, it would cease to have any moral authority. Moral adaptations are seen here as primarily facilitating 'low level morality'; or "morality" independent of motivation (e.g. social contract relationships, reciprocal altruism, Hamilton's rule, etc). This is in contrast to motivationally dependent 'high level morality' (morality as commonly understood).

The most rudimentary psychological basis for high level morality is itself a moral adaptation however; affective empathy, having evolved through its low level function; the encouragement of local altruism and the safety of the group's genes [63. Yet the effectiveness of a moral model based purely on affective empathy is limited by the health of dedicated emotional systems, including the capacity to regulate these (e.g. psychopathic traits; 64]). Likewise, the consistent application of empathy to high level morality relies on reasoning which is not itself adaptive.

Arguments have also been made for and against animal rights on the basis of their sentience. Singer 65] argues that all animals are equal on the basis of capacity to experience suffering; "A stone does not have interests because it cannot suffer. Nothing that we can do to it could possibly make any difference to its welfare" (p. 9). Much 
debate however exists in the literature 66. Some philosophers concur that conative sentience (capable of caring about themselves) implies moral significance [67]. Yet others have questioned the moral demands of sentience 68. Many focus on the capacity of self-awareness [69], being easier to determine than if a creature possesses mind. Some emphasise the importance of philosophy of mind (not only neuroscientific research) in resolving the dilemma [70]. Still others assume cognitive ability in general (including level of awareness) is mapped to moral obligations 71. Likewise, animal welfare policies are presumed to be dependent on the cognitive capacity of animals 72 . Finally, Sapontzis [73] has argued that moral rights should be based on both mind and virtue, irrespective of species.

\section{References}

1. Tangney JP, Stuewig J, Mashek DJ. Moral emotions and moral behavior. Annual review of psychology. 2007;58:345.

2. Gummerum M, Hanoch Y, Keller M, Parsons K, Hummel A. Preschoolers' allocations in the dictator game: The role of moral emotions. Journal of Economic Psychology. 2010;31(1):25-34.

3. Krettenauer T, Malti T, Sokol BW. The development of moral emotion expectancies and the happy victimizer phenomenon: A critical review of theory and application. International Journal of Developmental Science. 2008;2(3):221-235.

4. Malti T, Latzko B. Children's moral emotions and moral cognition: Towards an integrative perspective. New Directions for Child and Adolescent Development. 2010;2010(129):1-10.

5. Immordino-Yang MH. Me, my 'self' and you: Neuropsychological relations between social emotion, self-awareness, and morality. Emotion Review. $2011 ; 3(3): 313-315$.

6. Brownell C, Nichols SR, Svetlova M. Converging developments in prosocial behavior and self-other understanding in the second year of life: The second social-cognitive revolution. Oxford University Press New York; 2013.

7. Decety J, Michalska KJ, Kinzler KD. The contribution of emotion and cognition to moral sensitivity: a neurodevelopmental study. Cerebral Cortex. 2012;22(1):209-220.

8. Malti T, Ongley SF. The development of moral emotions and moral reasoning. In: Handbook of moral development. vol. 2. Psychology Press New York; 2014 . .

9. Hoffman ML. Empathy and moral development: Implications for caring and justice. Cambridge University Press; 2000.

10. Malti T, Keller M. The development of moral emotions in a cultural context. 2010;.

11. Greene J, Haidt J. How (and where) does moral judgment work? Trends in cognitive sciences. 2002;6(12):517-523.

12. Koenigs M, Young L, Adolphs R, Tranel D, Cushman F, Hauser M, et al. Damage to the prefrontal cortex increases utilitarian moral judgements. Nature. 2007;446(7138):908-911. 
13. Cox CL, Uddin LQ, Di Martino A, Castellanos FX, Milham MP, Kelly C. The balance between feeling and knowing: affective and cognitive empathy are reflected in the brain's intrinsic functional dynamics. Social cognitive and affective neuroscience. 2012;7(6):727-737.

14. Dvash J, Shamay-Tsoory SG. Theory of mind and empathy as multidimensional constructs: Neurological foundations. Topics in Language Disorders. $2014 ; 34(4): 282-295$.

15. Barclay P, Van Vugt M. The Evolutionary Psychology of Human Pro-sociality: Adaptations, Byproducts, and Mistakes. In: Schroeder D, Graziano W, editors. Oxford Handbook of Prosocial Behavior (Forthcoming). Oxford University Press; 2014. .

16. Singer T. The neuronal basis and ontogeny of empathy and mind reading: review of literature and implications for future research. Neuroscience \& Biobehavioral Reviews. 2006;30(6):855-863.

17. Gallese V, Keysers C, Rizzolatti G. A unifying view of the basis of social cognition. Trends in cognitive sciences. 2004;8(9):396-403.

18. Bastiaansen JA, Thioux M, Keysers C. Evidence for mirror systems in emotions. Philosophical Transactions of the Royal Society B: Biological Sciences. 2009;364(1528):2391-2404.

19. Bufalari I, Aprile T, Avenanti A, Di Russo F, Aglioti SM. Empathy for pain and touch in the human somatosensory cortex. Cerebral Cortex. $2007 ; 17(11): 2553-2561$.

20. Keysers C, Kaas JH, Gazzola V. Somatosensation in social perception. Nature Reviews Neuroscience. 2010;11(6):417-428.

21. Lamm C, Batson Cd, Decety J. The neural substrate of human empathy: effects of perspective-taking and cognitive appraisal. Cognitive Neuroscience, Journal of. 2007;19(1):42-58.

22. Bzdok D, Schilbach L, Vogeley K, Schneider K, Laird AR, Langner R, et al. Parsing the neural correlates of moral cognition: ALE meta-analysis on morality, theory of mind, and empathy. Brain Structure and Function. 2012;217(4):783-796.

23. Premack D, Woodruff G. Does the chimpanzee have a theory of mind? Behavioral and brain sciences. 1978;1(04):515-526.

24. Proust J. Metacognition and metarepresentation: is a self-directed theory of mind a precondition for metacognition? Synthese. 2007;159(2):271-295.

25. Lagattuta K, Weller D. Interrelations between theory of mind and morality: A developmental perspective. In: Handbook of moral development. 2nd ed. Psychology Press; 2014. p. 385-407.

26. Fu G, Xiao W, Killen M, Lee K. Moral Judgment and Its Relation to Second-Order Theory of Mind. Developmental psychology. 2014;.

27. Young L, Cushman F, Hauser M, Saxe R. The neural basis of the interaction between theory of mind and moral judgment. Proceedings of the National Academy of Sciences. 2007;104(20):8235-8240. 
28. Castelli I, Massaro D, Sanfey AG, Marchetti A. "What is fair for you?" Judgments and decisions about fairness and Theory of Mind. European Journal of Developmental Psychology. 2014;11(1):49-62.

29. Knobe J. Theory of mind and moral cognition: Exploring the connections. Trends in cognitive sciences. 2005;9(8):357-359.

30. Kohlberg L. The psychology of moral development: the nature and validity of moral stages. Essays on moral development. 2. Harper \& Row,; 1984.

31. Haidt J. The emotional dog and its rational tail: a social intuitionist approach to moral judgment. Psychological review. 2001;108(4):814.

32. Haidt J. Moral psychology for the twenty-first century. Journal of Moral Education. 2013;42(3):281-297.

33. Hauser MD. Moral minds: How nature designed our universal sense of right and wrong. Ecco New York; 2006. .

34. Rozin P, Lowery L, Imada S, Haidt J. The CAD triad hypothesis: A mapping between three moral emotions (contempt, anger, disgust) and three moral codes (community, autonomy, divinity). Journal of personality and social psychology. 1999 Apr;76(4):574-586.

35. Horberg E, Oveis C, Keltner D, Cohen A. Disgust and the Moralization of Purity. Journal of personality and social psychology. 2009 Dec;97(6):963-976.

36. Schnall S, Haidt J, Clore GL, Jordan AH. Disgust as Embodied Moral Judgment. Personality and Social Psychology Bulletin. 2008 Aug;34(8):1096-1109. PMID: 18505801.

37. Gutierrez R, Giner-Sorolla R. Anger, disgust, and presumption of harm as reactions to taboo-breaking behaviors. Emotion. 2007 Nov;7(4):853-868.

38. Suhler CL, Churchland P. Can innate, modular "foundations" explain morality? Challenges for Haidt's moral foundations theory. Journal of cognitive neuroscience. 2011;23(9):2103-2116.

39. Lapsley DK, Hill PL. On Dual Processing and Heuristic Approaches to Moral Cognition. Journal of Moral Education. 2008 Sep;37(3):313-332.

40. Turiel E. The Development of social knowledge: Morality and convention. Cambridge studies in social and emotional development. Cambridge Univ. Pr.,; 1983.

41. Kelly D, Stich S, Haley KJ, Eng SJ, Fessler DMT. Harm, Affect, and the Moral/Conventional Distinction. Mind \& Language. 2007;22(2):117-131.

42. Greene JD, Morelli SA, Lowenberg K, Nystrom LE, Cohen JD. Cognitive Load Selectively Interferes with Utilitarian Moral Judgment. Cognition. 2008 Jun;107(3):1144-1154.

43. Prinz J. Is morality innate? Moral psychology. 2008;1:367-406.

44. Ayala FJ. The difference of being human: Ethical behavior as an evolutionary byproduct. Biology, ethics, and the origins of life. 1995;p. 113-135.

45. Ayala FJ. Biology precedes, culture transcends: an evolutionist's view of human nature. Zygon. 1998;33(4):507-523. 
46. Keysers C, Gazzola V. Towards a unifying neural theory of social cognition. Progress in brain research. 2006;156:379-401.

47. Walker M, et al. Do We Have an Inborn Moral Sense? Open Journal of Philosophy. 2014;4(04):605.

48. Rai TS, Fiske AP. Moral psychology is relationship regulation: moral motives for unity, hierarchy, equality, and proportionality. Psychological review. 2011;118(1):57.

49. Barrett HC, Bolyanatz A, Crittenden AN, Fessler DM, Fitzpatrick S, Gurven M, et al. Small-scale societies exhibit fundamental variation in the role of intentions in moral judgment. Proceedings of the National Academy of Sciences. 2016;113(17):4688-4693.

50. Goodenough U, Deacon TW. From biology to consciousness to morality. Zygon. 2003;38(4):801-819.

51. Bartels DM, Pizarro DA. The Mismeasure of Morals: Antisocial Personality Traits Predict Utilitarian Responses to Moral Dilemmas. Cognition. 2011 Oct;121(1):154-161.

52. Aristotle. Nicomachean Ethics. 350BC;.

53. Hardy SA. Identity, reasoning, and emotion: An empirical comparison of three sources of moral motivation. Motivation and Emotion. 2006;30(3):205-213.

54. Bryan CJ, Adams GS, Monin B. When cheating would make you a cheater: Implicating the self prevents unethical behavior. Journal of Experimental Psychology: General. 2013;142(4):1001.

55. Baumeister RF, Smart L, Boden JM. Relation of threatened egotism to violence and aggression: the dark side of high self-esteem. Psychological review. $1996 ; 103(1): 5$.

56. Gallup GG, Platek SM. Cognitive empathy presupposes self-awareness: Evidence from phylogeny, ontogeny, neuropsychology, and mental illness. Behavioral and Brain Sciences. 2002;25(01):36-37.

57. Bloom P. Religion is natural. Developmental science. 2007;10(1):147-151.

58. Vohs KD, Schooler JW. The value of believing in free will encouraging a belief in determinism increases cheating. Psychological science. 2008;19(1):49-54.

59. Baumeister RF, Masicampo E, DeWall CN. Prosocial benefits of feeling free: Disbelief in free will increases aggression and reduces helpfulness. Personality and Social Psychology Bulletin. 2009;35(2):260-268.

60. Haslam N. Dehumanization: An integrative review. Personality and social psychology review. 2006;10(3):252-264.

61. Haslam N, Loughnan S. Dehumanization and infrahumanization. Annual review of psychology. 2014;65:399-423.

62. Haslam N, Loughnan S. Prejudice and dehumanization. In: Dixon J, Levine M, editors. Beyond Prejudice. Cambridge University Press; 2012. p. 89-104.

63. Decety J. The neuroevolution of empathy and caring for others: why it matters for morality. In: New frontiers in social neuroscience. Springer; 2014. p. 127-151. 
64. Avenanti A, Minio-Paluello I, Bufalari I, Aglioti SM. The pain of a model in the personality of an onlooker: influence of state-reactivity and personality traits on embodied empathy for pain. Neuroimage. 2009;44(1):275-283.

65. Singer P. Animal Liberation. Pimlico; 1975.

66. Sumner LW. The moral foundation of rights. 1987;.

67. Pluhar EB. Beyond prejudice: The moral significance of human and nonhuman animals. Duke University Press; 1995.

68. McCloskey HJ. Moral rights and animals. Inquiry. 1979;22(1-4):23-54.

69. Gallup GG. Do minds exist in species other than our own? Neuroscience \& Biobehavioral Reviews. 1986;9(4):631-641.

70. DeGrazia D. Taking animals seriously: mental life and moral status. Cambridge University Press; 1996.

71. Broom DM. Cognitive ability and awareness in domestic animals and decisions about obligations to animals. Applied Animal Behaviour Science. 2010;126(1):1-11.

72. Jones RC. Science, sentience, and animal welfare. Biology \& Philosophy. 2013;28(1):1-30.

73. Sapontzis SF. A critique of personhood. Ethics. 1981;91(4):607-618. 


\section{S2 Appendix - Surveys}

\section{Study 1 Survey 1 (International participants)}

Survey Title: "Basic Values Survey"

Instructions: "Complete a basic values survey. Overview -

In this task we need you to answer some basic values questions to the best of your ability.

Process - Read each question. Answer each question using the best of your ability

Thank you! - Thank you for your honest answers in this task." Questions

- How valuable do you consider animals?

- How valuable do you consider the currency?

- How valuable do you consider morality?

- How valuable do you consider democracy?

- How valuable do you consider safety?

- How valuable do you consider equality?

- How valuable do you consider happiness?

- How valuable do you consider resorts?

- How valuable do you consider authority?

- How valuable do you consider mind?

- How valuable do you consider national progress?

- How valuable do you consider integrity?

- How valuable do you consider loyalty?

- How valuable do you consider tax concessions for the disadvantaged?

- How valuable do you consider purity?

- How valuable do you consider the criminal justice system?

- How valuable do you consider the stock market?

- How valuable do you consider truth?

Multiple Choice Options

- not at all valuable

- not very valuable

- slightly valuable

- somewhat valuable

- very valuable

- extremely valuable

- utmost value

\section{Study 1 Survey 2 (USA participants)}

Survey Title: "Basic Values Survey"

Instructions: "Complete a basic values survey. Overview -

In this task we need you to answer some basic values questions to the best of your ability.

Process - Read each question. Answer each question using the best of your ability

Thank you! - Thank you for your honest answers in this task." Questions

- How valuable do you consider morality?

- How valuable do you consider prevention of harm?

- How valuable do you consider fairness?

- How valuable do you consider the currency? 
- How valuable do you consider authority?

- How valuable do you consider sentience (consciousness)?

- How valuable do you consider loyalty?

- How valuable do you consider integrity?

- How valuable do you consider purity?

Multiple Choice Options

- 1. not very valuable

- 2. somewhat valuable

- 3. significantly valuable

- 4. very valuable

- 5. especially valuable

- 6. extremely valuable

- 7. utmost value

\section{Study 1 Survey 3 (USA participants)}

Survey Title: "Basic Values Survey"

Instructions: "Complete a basic values survey. Overview -

In this task we need you to answer some basic values questions to the best of your ability.

Process - Read each question. Answer each question using the best of your ability

Thank you! - Thank you for your honest answers in this task." Questions

- How valuable do you consider morality?

- How valuable do you consider sanctity?

- How valuable do you consider care?

- How valuable do you consider honour?

- How valuable do you consider our mind (awareness)?

- How valuable do you consider integrity?

- How valuable do you consider disasters?

- How valuable do you consider fairness?

- How valuable do you consider loyalty?

- do you consider yourself to be more liberal or more conservative?

- Gender (optional)

Multiple Choice Options (values)

- 1. not very valuable

- 2. somewhat valuable

- 3. valuable

- 4. very valuable

- 5. especially valuable

- 6. extremely valuable

- 7. utmost value

Multiple Choice Options (political orientation)

- very liberal

- liberal

- more liberal

- more conservative

- conservative 
- very conservative

Multiple Choice Options (gender)

- male

- female

\section{Study 1 Survey 4 (USA participants)}

Survey Title: "Basic Values Survey"

Instructions: "Complete a basic values survey. Overview -

In this task we need you to answer some basic values questions to the best of your ability.

Process - Read each question. Answer each question using the best of your ability

Thank you! - Thank you for your honest answers in this task." Questions

- How valuable do you consider supporting another person in need?

- How valuable do you consider being loyal to another person?

- How valuable do you consider protecting another person in danger?

- How valuable do you consider catastrophes?

- How valuable do you consider being true to yourself and others?

- How valuable do you consider obeying another person in authority?

- How valuable do you consider maintaining yourself in purity?

- How valuable do you consider yourself (existence)?

- How valuable do you consider morality?

- Do you consider yourself to be more conservative or more liberal?

- Gender (optional)

Multiple Choice Options (values)

- 1. not very valuable

- 2. somewhat valuable

- 3. valuable

- 4. very valuable

- 5. especially valuable

- 6. extremely valuable

- 7. most extreme value

Multiple Choice Options (political orientation)

- very conservative

- conservative

- more conservative

- more liberal

- liberal

- very liberal

Multiple Choice Options (gender)

- male

- female 


\section{Study 1 Survey 5 (USA participants)}

Survey Title: "Values Survey"

Instructions: "Complete a values survey. Overview -

In this task we need you to answer some values questions to the best of your ability.

Process - Read and answer each question to the best of your ability

Thank you! - Thank you for your honest answers in this task."

5 A Questions

- How valuable do you consider morality?

- How valuable do you consider crime?

- How valuable do you consider integrity?

- How valuable do you consider equality?

- How valuable do you consider mind (consciousness)?

- Do you consider yourself to be more conservative or more liberal?

5A Multiple Choice Options (values)

- 1. not very valuable

- 2. somewhat valuable

- 3. valuable

- 4. very valuable

- 5. especially valuable

- 6. extremely valuable

- 7. most extreme value

5A Multiple Choice Options (political orientation)

- very conservative

- conservative

- more conservative

- more liberal

- liberal

- very liberal

Note in study 1 survey 5 part B, the order of the valuation questions were switched, including the order of liberal/conservative. In addition, the dummy variable 'equality' was replaced with 'care'.

5B Questions

- How valuable do you consider mind (consciousness)?

- How valuable do you consider care?

- How valuable do you consider integrity?

- How valuable do you consider crime?

- How valuable do you consider morality?

- Do you consider yourself to be more liberal or more conservative?

5B Multiple Choice Options (values)

- 1 . not very valuable

- 2. somewhat valuable

- 3. valuable

- 4. very valuable

- 5. especially valuable

- 6. extremely valuable

- 7. most extreme value 
5B Multiple Choice Options (political orientation)

- very liberal

- liberal

- more liberal

- more conservative

- conservative

- very conservative

\section{Study 1 Survey 6 (USA participants)}

Survey Title: "Values Survey"

Instructions: "Overview and Process -

Read and answer the questions to the best of your ability.

Thank you! - Thank you for your honest answers in this task.

(Note this survey is used for scientific research. There are 33 questions in total, and it should take around 5 minutes to complete. All questions have the same level of difficulty)."

6A Questions

- How valuable do you consider morality?

- How valuable do you consider chastity?

- How valuable do you consider authority?

- How valuable do you consider contemplation?

- How valuable do you consider fairness?

- How valuable do you consider care?

- How valuable do you consider loyalty?

- How valuable do you consider mind (sentience)?

- How valuable do you consider liberty (freedom)?

- How valuable do you consider modesty?

- How valuable do you consider industry (work ethic)?

- How valuable do you consider truth?

- How valuable do you consider crime?

- How valuable do you consider patience?

- How valuable do you consider integrity?

- How valuable do you consider justice?

- How valuable do you consider love?

- How valuable do you consider fortitude (courage in pain or adversity)?

- How valuable do you consider temperance (self-control)?

- How valuable do you consider faith (trust)?

- How valuable do you consider conscience?

- How valuable do you consider hope?

- How valuable do you consider prudence (wisdom)?

- How bad do you consider immorality?

- How bad do you consider subverting others?

- How bad do you consider degrading oneself?

- How bad do you consider not thinking about others?

- How bad do you consider happiness?

- How bad do you consider harming others?

- How bad do you consider betraying others?

- How bad do you consider cheating others?

- Gender (optional)

- Do you consider yourself to be more liberal or more conservative? 
Note in study 1 survey 6 part B, the order of three sets of valuation questions were switched.

6B Questions

- How valuable do you consider mind (sentience)?

- How valuable do you consider loyalty?

- How valuable do you consider care?

- How valuable do you consider fairness?

- How valuable do you consider contemplation?

- How valuable do you consider authority?

- How valuable do you consider chastity?

- How valuable do you consider morality?

- How valuable do you consider prudence (wisdom)?

- How valuable do you consider hope?

- How valuable do you consider conscience?

- How valuable do you consider faith (trust)?

- How valuable do you consider temperance (self-control)?

- How valuable do you consider fortitude (courage in pain or adversity)?

- How valuable do you consider love?

- How valuable do you consider justice?

- How valuable do you consider integrity?

- How valuable do you consider patience?

- How valuable do you consider crime?

- How valuable do you consider truth?

- How valuable do you consider industry (work ethic)?

- How valuable do you consider modesty?

- How valuable do you consider liberty (freedom)?

- How bad do you consider cheating others?

- How bad do you consider betraying others?

- How bad do you consider harming others?

- How bad do you consider happiness?

- How bad do you consider not thinking about others?

- How bad do you consider degrading oneself?

- How bad do you consider subverting others?

- How bad do you consider immorality?

- Gender (optional)

- Do you consider yourself to be more liberal or more conservative?

Multiple Choice Options (positive values)

- 1. not very valuable

- 2. somewhat valuable

- 3. quite valuable

- 4. very valuable

- 5. especially valuable

- 6. extremely valuable

- 7. most extreme value

Multiple Choice Options (negative values)

- 1. not very bad

- 2. somewhat bad

- 3. quite bad

- 4. very bad

- 5. especially bad 
- 6. extremely bad

- 7. most extreme bad

Multiple Choice Options (gender)

- male

- female

Multiple Choice Options (political orientation)

- very liberal

- liberal

- more liberal

- more conservative

- conservative

- very conservative

\section{Study 2 Survey (USA participants)}

Survey Title: "Values Survey"

Instructions: "Overview and Process -

Read and answer the questions to the best of your ability.

Thank you! - Thank you for your honest answers in this task." Key

- Manipulation $\mathrm{A}=$ "Jasmine doesn't think much about anything."

- Manipulation B = "Jasmine thinks a lot about many things."

- Manipulation $\mathrm{C}=$ "Jasmine doesn't care much about anyone."

- Manipulation D = "Jasmine cares a lot about many people."

- Manipulation $\mathrm{E}=$ "'"

Questions

- (Insert Manipulation A/B/C/D/E) How important is the moral treatment of Jasmine?

- How important are extremely unimportant things (by definition)?

- Gender (optional)

- Do you consider yourself to be more liberal or more conservative?

Multiple Choice Options (values)

- 1. not at all important

- 2. somewhat important

- 3. quite important

- 4. very important

- 5. especially important

- 6. extremely important

- 7. utmost importance

Multiple Choice Options (gender)

- male

- female

Multiple Choice Options (political orientation)

- very liberal

- liberal 
- more liberal

- more conservative

- conservative

- very conservative

\section{Study 3 Survey 1 (International and USA participants)}

Survey Title: "Values Survey"

Instructions: "Overview and Process -

Read and answer the questions to the best of your ability (with your opinion).

Thank you! - Thank you for your honest answers in this task.

(Note this survey is used for scientific research)."

Questions

- Morality applies to;

- Do only human beings have a mind?

- do you consider yourself to be more liberal or more conservative?

- Gender (optional)

- What do you think integrity means? (in one sentence please give your opinion; without using a dictionary/encyclopedia)

Multiple Choice Options ('Morality applies to')

- 1. all creatures

- 2. all creatures with a mind

- 3. human beings only

- 4. some human beings only

Multiple Choice Options ('Do only human beings have a mind?')

- yes

- no

Multiple Choice Options (political orientation)

- very liberal

- liberal

- more liberal

- more conservative

- conservative

- very conservative

Multiple Choice Options (gender)

- male

- female

\section{Study 3 Survey 2 (USA participants)}

Survey Title: "Values Survey"

Instructions: "Overview and Process -

Read and answer the questions to the best of your ability (with your opinion).

Thank you! - Thank you for your honest answers in this task.

(Note this survey is used for scientific research)."

Questions

- Morality applies to; 
- Do only human beings have a mind?

- do you consider yourself to be more liberal or more conservative?

- Gender (optional)

- What do you think integrity means? (in one sentence please give your opinion; without using a dictionary/encyclopedia)

Multiple Choice Options ('Morality applies to')

- 1. all creatures

- 2. all creatures with a mind (including humans)

- 3. human beings only

- 4. some human beings only

Multiple Choice Options ('Do only human beings have a mind?')

- yes

- no

Multiple Choice Options (political orientation)

- very liberal

- liberal

- more liberal

- more conservative

- conservative

- very conservative

Multiple Choice Options (gender)

- male

- female

\section{Study 3 Survey 3 (USA participants)}

Survey Title: "Values Survey"

Instructions: "Overview and Process -

Read and answer the questions to the best of your ability (with your opinion).

Thank you! - Thank you for your honest answers in this task.

(Note this survey is used for scientific research)."

Questions

- Morality applies to;

- Do only human beings have a mind?

Multiple Choice Options ('Morality applies to')

- 1. all creatures

- 2. all creatures with a mind (including humans)

- 3. human beings only

- 4. some human beings only

Multiple Choice Options ('Do only human beings have a mind?')

- yes (human beings only)

- no (some other creatures also) 


\section{Study 3 Survey 4 (USA participants)}

Survey Title: "Values Survey"

Instructions: "Overview and Process -

Read and answer the questions to the best of your ability (with your opinion).

Thank you! - Thank you for your honest answers in this task.

(Note this survey is used for scientific research)."

Questions

- Morality applies to;

- Do only human beings have a mind?

- Do all creatures have a mind?

- Do you consider yourself to be more liberal or more conservative?

- Gender (optional)

Multiple Choice Options ('Morality applies to')

- 1. all creatures

- 2. all creatures with a mind (including humans)

- 3. human beings only

- 4. some human beings only

Multiple Choice Options ('Do only human beings have a mind?')

- yes (human beings only)

- no (some other creatures also)

Multiple Choice Options ('Do all creatures have a mind?')

- yes

- no

Multiple Choice Options (political orientation)

- very liberal

- liberal

- more liberal

- more conservative

- conservative

- very conservative

Multiple Choice Options (gender)

- male

- female

\section{Study 4 Survey (USA participants)}

Survey Title: "Values Survey"

Instructions: "Overview and Process -

Read and answer the questions to the best of your ability. Each question requires you to perform a rating based on your opinion (select the most appropriate value between 1 and 10).

Thank you! - Thank you for your honest answers in this task.

(Note this survey is used for scientific research. There are 24 questions in total, and it should take 2-3 minutes to complete carefully)."

Questions 
- How important is the moral treatment of a human being?

- How important is the moral treatment of a dolphin?

- How important is the moral treatment of a bacterium?

- How important is the moral treatment of your local politician?

- How important is the moral treatment of your mother?

- How important is the moral treatment of a wild hyena?

- How important is the moral treatment of your best friend?

- How important is the moral treatment of a pet dog?

- How important is the moral treatment of a rock?

- How important is the moral treatment of an exotic dancer?

- How important is the moral treatment of a teacher?

- How important is the moral treatment of a thief?

- How much self-awareness does your mother have?

- How much self-awareness does a bacterium have?

- How much self-awareness does a dolphin have?

- How much self-awareness does an exotic dancer have?

- How much self-awareness does your local politician have?

- How much self-awareness does a human being have?

- How much self-awareness does a wild hyena have?

- How much self-awareness does a teacher have?

- How much self-awareness does a rock have?

- How much self-awareness does a pet dog have?

- How much self-awareness does your best friend have?

- How much self-awareness does a thief have?

Ten level Likert scale labels ('How important is the moral treatment of x?')

- 1. not important

- 10. extremely important

Ten level Likert scale labels ('How much self-awareness does x have?')

- 1. no self-awareness

- 10. very high self-awareness

\section{Study 5 Survey (USA participants)}

Survey Title: "Values Survey"

Instructions: "Overview and Process -

Read and answer the questions to the best of your ability. The first 2 questions [Part B: "These questions"] require you to perform a rating based on your opinion (select the most appropriate value between 1 and 10).

Thank you! - Thank you for your honest answers in this task.

(Note this survey is used for scientific research. There are 3 questions [Part B: "2 questions"] in total, and it should take 1-2 minutes [Part B: "approximately 1 minute"] to complete).

[Part A only: A philosophical zombie is a hypothetical creature which is physically identical to a human being but has no internal mental reality. It looks the same as a human being, relates the same, talks the same. Its brain and body function perfectly according to the laws of physics. A philosophical zombie's brain processes colour, movement, noise, and emotion information, but it does not see, hear, or feel anything. It appears to be conscious and sentient but it is not.]

[Part C only: A philosophical phantom is a hypothetical creature which is physically identical to an inanimate object but has an internal mental reality. It might look the 
same as a rock, relate the same, move the same. Its matter functions perfectly according to the laws of physics. A philosophical phantom's matter does not process colour, movement, noise, and emotion information, but it sees, hears, and feels things. It doesn't appear to be conscious and sentient but it is.] Questions

- What is the moral worth of a philosophical zombie? [Part A only]

- What is the moral worth of a human being? [Part B only]

- What is the moral worth of a philosophical phantom? [Part C only]

- What is the moral worth of a rock (not a phantom [Part C only])?

- What is a philosophical zombie (according to the introduction)? [Part A only]

Ten level Likert scale labels ('What is the moral worth of $\mathrm{x}$ ?')

- 1. not valuable

- 10. extremely valuable

Multiple Choice Options ('What is a philosophical zombie?') [Part A only]

- A. An undead creature featured in the movies

- B. A hypothetical physical being without an internal mental reality

- C. An illogical concept (if an observer requires a brain, then a brain logically requires an observer. According to 'the new laws of implication'; if $\mathrm{A}->\mathrm{B}$, then $\mathrm{B}->\mathrm{A})$

- D. A creature that sees red as blue and blue as green

- E. A physical being with multiple internal mental realities; some of whom see yellow as blue, and others whom see purple as orange

Multiple Choice Options ('What is a philosophical phantom?') [Part C only]

- A. An undead creature featured in the movies

- B. A hypothetical inanimate object with an internal mental reality

- C. An illogical concept (if one observer requires a brain, then every observer requires a brain. According to 'the new laws of implication'; if $\mathrm{A} 1->\mathrm{B}$, then $\mathrm{A} 2->\mathrm{B})$

- D. A creature that sees red as blue and blue as green

- E. A physical being with multiple internal mental realities; some of whom see yellow as blue, and others whom see purple as orange 


\section{S3 Appendix - Bad data filtering}

There were some issues interpreting the strength of the correlations derived from study 1 parts $\mathrm{P} 1$ and $\mathrm{P} 2$, which were resolved in future parts/studies. Bad data were confirmed present in both study 1 parts P1 and P2 (based on manual inspection), meaning not every participant was providing accurate answers. This may have either artificially increased or decreased the correlations. They could have been artificially decreased if one or more answers provided were given at random. Likewise they could have been increased if one or more participants were forging their answers. Given the nature of the experimental process (crowd sourcing), it was expected that some participants might anticipate a positive correlation between the variables of interest and therefore fabricate such in their answers. This would enable them to save time, without having to attend to the content of specific questions.

Study 1 parts P3, P4, P5, and P6 corrected for this by taking much larger sample sizes and including a negative dummy variable ("how valuable do you consider disasters/catastrophes/crime/crime?"). The number of remaining bad data entries was estimated based on the number of participants responding to this question with "valuable"/"very valuable"/"somewhat valuable"/"somewhat valuable" or greater. It can be confirmed that such a filter was rigorous in terms of hits; the successful detection and removal of bad data (though not necessarily in terms of false positives - the categorisation of good data as bad data).

In study $1 \mathrm{P} 3$, the probability of a participant randomly selecting "not very valuable" (1) or "somewhat valuable" (2) when answering the dummy variable question was, $\mathrm{p}=0.04(\approx 95 \%$ rejection rate). This probability value was calculated based on the probability of a participant selecting 1 or 2 to any question preceding (or not including) the dummy variable (i.e. morality, sanctity, care, honour, our mind, integrity), assuming the participant was following some pseudorandom or predictive selection pattern. This filter could also have been set at "very valuable" or greater in P3, with no difference to the results (based on the still low number of people choosing option 'very valuable' or less at random; $\mathrm{p}=0.10$ ).

Study $1 \mathrm{P} 4$ used the more relaxed filter discussed above to reduce false positives, providing an estimated bad data acceptance; $\mathrm{p}=0.09$ ( $\approx 90 \%$ rejection rate).

Study 1 P5 used a stronger filter based on valuation of crime. The only response accepted to this question was "not very valuable" (1). This resulted in an estimated bad data acceptance rate; $\mathrm{p}=0.004(\approx 99 \%$ rejection rate), although in this case partial survey fabrication by participants would become the dominant factor (and its frequency cannot easily be estimated).

Study 1 P6 used the previous filter based on valuation of crime (see above), and a second filter for the negative valuations based on happiness ("how bad do you consider happiness"). P6 accepted participants who answered at least one of these items correctly: "not very valuable/bad" (1). Out of the 220 participants filtered (from the original 250), 170 passed the first dummy variable check, 210 passed the second (clearer) dummy variable check, and 160 passed both dummy variable checks. Frequency analysis of the first dummy variable indicates participants were consistently responding low for this item (compared to the non dummy variables), but were often selecting '2' ("somewhat valuable") instead of ' 1 ' ("not very valuable") for this response. 22 participants selected response ' 2 '; which was greater than any other response for this question (besides ' 1 '), and would be an unusually low response to make for a non-dummy variable question. When enforcing both filters (rather than just one of them), and using a more relaxed criteria for the second filter $(<=2$ rather than $=1)$, the correlations between both morality and mind $(r(175)=0.22, p=.004$ : hypothesis $1 \mathrm{~A})$, and morality and integrity $(r(175)=0.46, p<.001$ : hypothesis $1 \mathrm{~B})$ are identical to what has been reported. P6 also attempted to increase participant accuracy rate by 
adding instructions indicating the purpose of the study (i.e. scientific research), the number of questions, the approximate completion time, and an assurance that the questions did not increase in difficulty (such that participants did not feel inclined to rush at the beginning). These instructions were developed based on an online forum requesting feedback from crowd source workers on how they might be encouraged to answer research surveys more accurately.

Study 2 used an even stronger filter based on a question with only one correct answer, "How important are extremely unimportant things (by definition)?"; "not at all important" (1).

Study 3 P1 and P2 filtering was conducted based on participant response to question "what do you think integrity means". If the participant did not respond accurately to this question they were removed from the analysis. Based on the low bad data detection in study $3 \mathrm{P} 1$ and $\mathrm{P} 2$ (28; i.e. 11\%), and the high correspondence in the results between parts $\mathrm{P} 1 / \mathrm{P} 2$ and $\mathrm{P} 3 / \mathrm{P} 4$, bad data were not considered a significant problem in parts $\mathrm{P} 3$ and P4. Therefore a dedicated, strict performance filter was not employed. P3 did not apply a filter. P4 applied a filter based on participant response to questions 2 and 3 . If the participant responded 'yes' to both question 2 ('Do only human beings have a mind?') and question 3 ('Do all creatures have a mind?') they were removed from the data analysis. The number of participants removed (13; i.e. $8 \%$ ) based on this weak filter was considered evidence of a relatively high participant accuracy experienced in parts P3 and P4 overall. Note although it targeted the most common fabrication answer path and is expected to capture a significant proportion of bad data, it is not robust.

Study 4 filtering was conducted based on participant response to questions; "how important is the moral treatment of a rock", "how much self-awareness does a rock have", "how important is the moral treatment of a bacterium", and "how much self-awareness does a bacterium have". Data were only accepted for participants if their responses to these questions fell below 8, 2, 8, and 8 respectively. Most (27 out of 38) bad data were successfully filtered based on participant response to the question "how much self-awareness does a rock have". The participant had to respond "1" (no self-awareness) to this question for their data to be used in the analysis.

Study 5 filtering was conducted based on participant response to question; "What is the moral worth of a rock?". Data were only accepted for participants if their response to this question fell below 6 . Study 5 part A/C implemented an additional filter based on the manipulation check (question 3); "What is a philosophical zombie/phantom (according to the introduction)?". Participants responses were only accepted if they answered this multiple choice question correctly, i.e. "B. A hypothetical physical being without an internal mental reality", or "B. A hypothetical inanimate object with an internal mental reality".

Finally, the normalisation process for likert/ordinal data has the potential to affect the overall/absolute correlation values. This includes participant baseline correlation between all items (irrespective of their content).

A maximum 15 minutes survey completion time was enforced for study 1 P1 to P5, a maximum 30 minutes survey completion time was enforced for study $1 \mathrm{P} 6$, and a maximum 10 minutes survey completion time was enforced for study 2 . In order to discourage fabrication, a minimum 30 second survey completion time was enforced for study 1 P2, P3, and P4, 20 second survey completion time for study 1 P5, 120 second survey completion time for study 1 P6, 16 second survey completion time for study 2, 10 second survey completion time for study 3,120 second survey completion time for study 4, and 30 second (Part B: 15 second) survey completion time for study 5. Study 3 P1 and P2 relied upon users providing an appropriate textual response to question 5 (and as such the minimum response time was not considered relevant). Study 3 P3 asked only 2 questions (for which the study 3 P3 and P4 minimum response time was calibrated). 
The study 1 P1 survey was conducted with a moderate contributor level performance threshold (the top $60 \%$ of CrowdFlower contributors as judged by accuracy). The remaining surveys were conducted with highest level contributors only (the top $7 \%$ of CrowdFlower contributors as judged by accuracy). 


\section{S4 Appendix - Significance of mind measures}

Validation of the significance of mind measure integrity was performed by evaluating the definitions of integrity collated in study 3 parts P1 and P2. Participant answers to study 3 question 5 ('What do you think integrity means?') were rated based on a number of (post-hoc) identified response criterion. All 250 (222 final) participants had their integrity definition response rated. Only explicit references to rated concepts were accepted. $47 \%$ of participants were rated as defining integrity as a form of honesty, $50 \%$ were rated as defining integrity as a form of moral consistency, $27 \%$ were rated as defining integrity as a form of integration, $7 \%$ were rated as defining integrity as a form of moral strength, $4 \%$ were rated as defining integrity as a form of respect, $4 \%$ were rated as defining integrity as a form of relativism, and $2 \%$ were rated as defining integrity as a form of conscience.

Study 3 suggests that participants defined integrity in accordance with a significance of mind concept, with a significant proportion viewing it as being self-directed. While $50 \%$ of people viewed integrity as a form of (general) moral consistency (dyadic/self-directed significance of mind), $47 \%$ viewed integrity as a form of interpersonal or intrapersonal honesty (dyadic/self-directed significance of mind), and $27 \%$ viewed integrity as a form of intrapersonal integration (self-directed significance of mind). Its interpretation as implying both integration and intrapersonal honesty (along with interpersonal and moral consistency) support its use as a complete (non-exclusively dyadic) significance of mind measure.

Additional examination of the significance of mind construct was performed using mediation analysis of the significance of mind measures with respect to valuation of neutral mind and valuation of morality. In all study 1 parts, the association between valuation of morality and the significance of mind measures was partially mediated by valuation of mind (no causal assumption). Table 1 demonstrates the degree to which the association between morality and the significance of mind measures can be explained by neutral mind, as derived from regression analysis.

Furthermore, regression analysis indicated that the significance of mind measure, integrity, was uniquely predicted by both dyadic (care) and self-directed (purity) morality (across study 1 parts 1, 2, 3, 4, and 6). See Table 2. Finally, the purity foundation was moderately associated with integrity (across all study 1 parts). See Table 3 Its average association with integrity was $r=0.34$, versus $0.32,0.23,0.45$, and 0.29 ; for the care, fairness, authority, and loyalty foundations respectively.

\section{Discussion}

The dictionary definition of integrity includes allusions to morality ('moral principles'). Its association with morality could simply be an equation of concepts. Yet the definitions collected in study 3 (P1 and P2) suggest the integrity-morality association is not simply an equation of concepts, and that integrity is measuring significance of mind (to at least some degree). Study 3 indicates that while $50 \%$ of people view integrity as a form of (general) moral consistency, $50 \%$ view integrity as a form of interpersonal or intrapersonal honesty, and 30\% view integrity as a form of intrapersonal integration. Similarly, the pre-existence of models of morality in society (e.g. integrity) suggests there are some behaviours and character traits more closely associated with morality than others. These should be a useful guide to identifying a physical basis for morality. The consistently strong association between integrity and morality indicates that irrespective of people's precise definition of integrity, people seem to retain an association between morality and an internal, united, process or state (contrary to what might be expected from a modular system).

Furthermore, its interpretation as implying (self-directed) integration and 
Table 1. Association between morality and significance of mind (as mediated by neutral mind)

\begin{tabular}{|l|r|r|r|r|r|r|r|r|r|r|}
\hline Measure & \multicolumn{7}{|c|}{ Association with morality (wo mind) } & \multicolumn{7}{|c|}{ Association with morality (w mind) } \\
\hline & $\beta$ (r) & df & p & CImin & CImax & $\beta$ & df & p & CImin & CImax \\
\hline S1 P1 & & & & & & & & & & \\
\hline mind & 0.26 & 148 & $<.001$ & 0.10 & 0.42 & & & & & \\
integrity & 0.46 & 148 & $<.001$ & 0.32 & 0.61 & 0.38 & 147 & $<.001$ & 0.24 & 0.52 \\
\hline S1 P2 & & & & & & & & & & \\
\hline mind & 0.50 & 148 & $<.001$ & 0.37 & 0.64 & & & & & \\
integrity & 0.60 & 148 & $<.001$ & 0.47 & 0.73 & 0.41 & 147 & $<.001$ & 0.28 & 0.55 \\
\hline S1 P3 & & & & & & & & & & \\
\hline mind & 0.38 & 148 & $<.001$ & 0.21 & 0.56 & & & & & \\
integrity & 0.61 & 148 & $<.001$ & 0.47 & 0.73 & 0.50 & 147 & $<.001$ & 0.36 & 0.63 \\
\hline S1 P4 & & & & & & & & & & \\
\hline mind & 0.43 & 160 & $<.001$ & 0.29 & 0.57 & & & & & \\
integrity & 0.48 & 160 & $<.001$ & 0.34 & 0.62 & 0.37 & 159 & $<.001$ & 0.22 & \\
\hline S1 P5 & & & & & & & & & & \\
\hline mind & 0.34 & 254 & $<.001$ & 0.22 & 0.46 & & & & & \\
integrity & 0.58 & 254 & $<.001$ & 0.45 & 0.64 & 0.47 & 253 & $<.001$ & 0.37 & \\
\hline S1 P6 & & & & & & & & & & \\
\hline mind & 0.21 & 218 & 0.002 & 0.08 & 0.34 & & & & & \\
integrity & 0.47 & 218 & $<.001$ & 0.35 & 0.58 & 0.41 & 217 & $<.001$ & 0.30 & \\
contemplation & 0.26 & 218 & $<.001$ & 0.13 & 0.39 & 0.16 & 217 & .007 & 0.53 & \\
conscience & 0.34 & 218 & $<.001$ & 0.21 & 0.46 & 0.27 & 217 & $<.001$ & 0.15 & 0.39 \\
\hline
\end{tabular}

Table 2. Regression analysis of integrity as predicted by dyadic (care) and self-directed (purity) morality

\begin{tabular}{|l|r|r|r|r|r|r|}
\hline Foundation & sr & df & $\mathbf{t}$ & $\mathbf{p}$ & CImin & CImax \\
\hline S1 P1 & & & & & & \\
\hline care & 0.26 & 147 & 3.62 & $<.001$ & 0.12 & 0.40 \\
purity & 0.28 & 147 & 3.79 & $<.001$ & 0.14 & 0.41 \\
\hline S1 P2 & & & & & & \\
\hline care & 0.58 & 147 & 10.22 & $<.001$ & 0.49 & 0.68 \\
purity & 0.21 & 147 & 3.73 & $<.001$ & 0.10 & 0.33 \\
\hline S1 P3 & & & & & & \\
\hline care & 0.34 & 147 & 4.76 & $<.001$ & 0.21 & 0.47 \\
purity & 0.21 & 147 & 2.98 & .003 & 0.07 & 0.35 \\
\hline S1 P4 & & & & & & \\
\hline care & 0.47 & 159 & 7.16 & $<.001$ & 0.36 & 0.59 \\
purity & 0.17 & 159 & 2.57 & .011 & 0.04 & 0.30 \\
\hline S1 P6 & & & & & & \\
\hline care & 0.43 & 217 & 7.34 & $<.001$ & 0.33 & 0.54 \\
purity & 0.10 & 217 & 1.72 & .087 & -0.01 & 0.22 \\
\hline
\end{tabular}

intrapersonal honesty, along with (dyadic) interpersonal and (non-specific) moral consistency support its use as a complete (not exclusively dyadic) significance of mind measure. Regression analysis from study 1 parts P1 to P6 indicated that integrity was explained by both dyadic (care) and self-directed (purity) morality. Likewise, the purity foundation was moderately associated with integrity (across all parts). This challenges the contextual requirement of a dyadic relationship between agent and patient for morality. Similarly, the moderately strong association between integrity and valuation of neutral mind suggests that the process likely has a self-reflective component. In all study 
Table 3. Association between the purity foundation and all other foundations

\begin{tabular}{|l|r|r|r|r|r|}
\hline Foundation & $\beta(\mathbf{r})$ & $\mathbf{d f}$ & $\mathbf{p}$ & CImin & CImax \\
\hline S1 P1 & & & & & \\
\hline care & 0.35 & 148 & $<.001$ & 0.20 & 0.48 \\
fairness & 0.15 & 148 & .073 & -0.01 & 0.30 \\
authority & 0.41 & 148 & $<.001$ & 0.27 & 0.54 \\
loyalty & 0.25 & 148 & .003 & 0.09 & 0.39 \\
integrity & 0.39 & 148 & $<.001$ & 0.25 & 0.52 \\
morality & 0.30 & 148 & $<.001$ & 0.15 & 0.44 \\
\hline S1 P2 & & & & & \\
\hline care & 0.32 & 148 & $<.001$ & 0.17 & 0.45 \\
fairness & 0.29 & 148 & $<.001$ & 0.13 & 0.43 \\
authority & 0.37 & 148 & $<.001$ & 0.22 & 0.50 \\
loyalty & 0.34 & 148 & $<.001$ & 0.19 & 0.48 \\
integrity & 0.42 & 148 & $<.001$ & 0.28 & 0.54 \\
morality & 0.47 & 148 & $<.001$ & 0.33 & 0.58 \\
\hline S1 P3 & & & & & \\
\hline care & 0.41 & 148 & $<.001$ & 0.26 & 0.53 \\
fairness & 0.31 & 148 & $<.001$ & 0.16 & 0.45 \\
authority & 0.43 & 148 & $<.001$ & 0.29 & 0.55 \\
loyalty & 0.34 & 148 & $<.001$ & 0.19 & 0.47 \\
integrity & 0.38 & 148 & $<.001$ & 0.24 & 0.51 \\
morality & 0.56 & 148 & $<.001$ & 0.44 & 0.66 \\
\hline S1 P4 & & & & & \\
\hline care & 0.19 & 160 & .016 & 0.04 & 0.33 \\
fairness & 0.22 & 160 & .006 & 0.06 & 0.36 \\
authority & 0.51 & 160 & $<.001$ & 0.38 & 0.61 \\
loyalty & 0.26 & 160 & $<.001$ & 0.11 & 0.40 \\
integrity & 0.28 & 160 & $<.001$ & 0.13 & 0.42 \\
morality & 0.52 & 160 & $<.001$ & 0.40 & 0.62 \\
\hline S1 P6 & & & & & \\
\hline care & 0.32 & 218 & $<.001$ & 0.19 & 0.43 \\
fairness & 0.17 & 218 & .013 & 0.04 & 0.29 \\
authority & 0.52 & 218 & $<.001$ & 0.41 & 0.61 \\
loyalty & 0.27 & 218 & $<.001$ & 0.14 & 0.39 \\
integrity & 0.25 & 218 & $<.001$ & 0.12 & 0.37 \\
morality & 0.37 & 218 & $<.001$ & 0.25 & 0.48 \\
\hline
\end{tabular}

1 parts (P1 to $\mathrm{P} 6)$, the correlation between valuation of morality and the significance of mind measures was partially mediated by valuation of mind (no causal assumption). In accordance with the underlying theory, this suggests that people associate morality with significance of mind, and that this is associated with their valuation of neutral mind.

\section{Purity neutral self-directed significance of mind measures}

The moderate association between the purity neutral self-directed significance of mind measures (contemplation, conscience) and morality in study 1 P6 supports the relevance of self-directed mind perception to morality. Moreover, the fact these were purity foundation neutral suggests that the purity foundation may actually be capturing part of a more general self-directed moral construct. The purity foundation neutral self-directed significance of mind measures were however less strongly associated with 
morality than the non-exclusively dyadic measure integrity.

Furthermore, study 2 produced evidence that ostensibly self-directed significance of mind (perceived scope and intensity of thought) influenced moral worth judgements. Moreover, it suggests that purity foundation neutral self-directed significance of mind is perhaps as important in determining moral worth judgements as perceived care.

Self-directed significance of mind may however have acted as an indicator of a third variable, and this could have driven its association with morality. It is possible that dyadic significance of mind (care) was being inferred from the self-directed significance of mind measures in study 1 P6 and study 2. The predictions of the model for self and other-directed morality were however supported by the preliminary moral foundations analysis (see S5 Appendix).

\section{Supporting Information}

\section{S1 Appendix}

\section{S2 Appendix}

\section{S3 Appendix}

\section{S4 Appendix}

\section{S5 Appendix}

\section{S6 Appendix}

\section{S7 Appendix}




\section{S5 Appendix - Model predictions for self and other-directed morality}

\section{The model of morality}

The theory predicts that morality operates on both a high valuation of general mind (neutral sentience), and high valuation of specific mind (specific mind that acts in accordance with a high valuation of general mind). High valuation of general mind is a direct consequence of the nature of the organism's theory of mind (evolved belief in mental properties). This conception of mind is logically extended (projected) to like others, and may be socialised in children (resulting in the conditioning of emotions). High valuation of specific mind is a direct consequence of the high valuation of general mind, as experience of human uniqueness supports its belief in valuable mental properties. The creature has a cognitive desire for evidence of mental (internal) significance, in both itself, and others to whom mind has been projected. Likewise, witness of mental significance provides feedback on the existence of general mind.

Significance of mind is defined here as the extent to which a mind is contextually important; the value of a person's mind in the context of the world around them and their interactions with others, including their relationship with themselves and their unconscious subsystems. It is therefore proposed that morality is both self-directed and other-directed (dyadic). Likewise, self and other directed morality is perceived in both oneself and others (to whom mind has been projected). Similar to what has been proposed by Moral Dyad theory [1], the same basic template is applied to one's own care for self and others, as one's perception of another's care for self and others. When evaluating morality (one's own or another's), a two foundation taxonomy should be able to account for more variance in moral judgement than a single foundation taxonomy (e.g. Moral Dyad theory), and as much variance in moral judgement than any more extensive taxonomy (e.g. Moral Foundations theory; 2]).

Contrary to the theory being proposed, the moral type casting hypothesis of Gray and Wegner [3] supposes that the roles of moral patient and moral agent are mutually exclusive. The objectification manipulations of Holland 4] however demonstrate a simultaneous reduction of both moral patiency and moral agency. The dissociation observed [5] could therefore be a consequence of relative expectations of agentic (versus sentinel) significance being highly sensitive to preconceptions of an individual's mind. Unlike what has been emphasised in H. Gray et al. [5] and Gray et al. 1], it is proposed that the dimensions of experience (general mind) and agency (significance of mind) are not independent, but dependent on the perception of general mind. As such, the moral patiency and moral agency constructs may be interdependent. Supporting this position, $88 \%$ of the variance of the factor analysis of mean mental capacities (e.g. capacity to feel pain) across characters (e.g. baby) was explained by experience, while only $8 \%$ of the variance was explained by agency [5].

Likewise, the moral dyad hypothesis of Gray et al. [1] assumes that morality is a dyadic process between persons. The Purity foundation in Moral Foundations theory however is not obviously dyadic, with many violations involving harm to (disrespect of) spiritual self [6] rather than others [7]. Moreover, the purity foundation was formally conceived as being self-directed [8]. Evidence also suggests that the harm and purity foundations differ by the target of the action [9].

Although the prospect of reconciling Moral Foundations theory will not be stressed here, there exists evidence that the moral domain may be predicted by a two foundation taxonomy [10]. A dissociation has been identified between the Binding (Ingroup, Authority, Purity) and Individualising (Care, Fairness) subdomains [2, 11, 12]. In this respect, it is feasible that the individualising foundations are a reflection of dyadic 
morality, and the binding foundations are a reflection of self-directed morality. Loyalty can be expressed either as 'being true to your word' (not necessarily dyadic) or as caring for another person by being loyal to them (dyadic). Likewise, obedience to authority (as independent of care) is not necessarily a reflection of one's respect for an external principle independent of its respect for spiritual self. Furthermore, as highlighted above, the purity foundation is especially oriented towards self-directed morality.

While some measures of purity might be expressions of dyadic morality [1, it is not clear that this observation generalises to all purity violations. Furthermore, the fact dyadic morality may be found applicable to a purity violation [13] does not of itself negate the presence of a purity violation. Its moral applicability would have to be demonstrated as driven entirely by the dyadic care component. Supporting such scepticism, Schein and Gray [14] found a systematic deviation between the purity foundation and all other moral foundations (study 5). Similarly, in rating a variety of purity scenarios, roughly $20 \%$ of participants viewed harm as being directed towards the perpetrator [13. It is likely that the purity foundation (and all non-dyadic morality) concerns care for someone however; the spiritual self. In this sense their thesis aligns with the model proposed (see Fig. 11).

\section{Significance of Mind (Morality)}

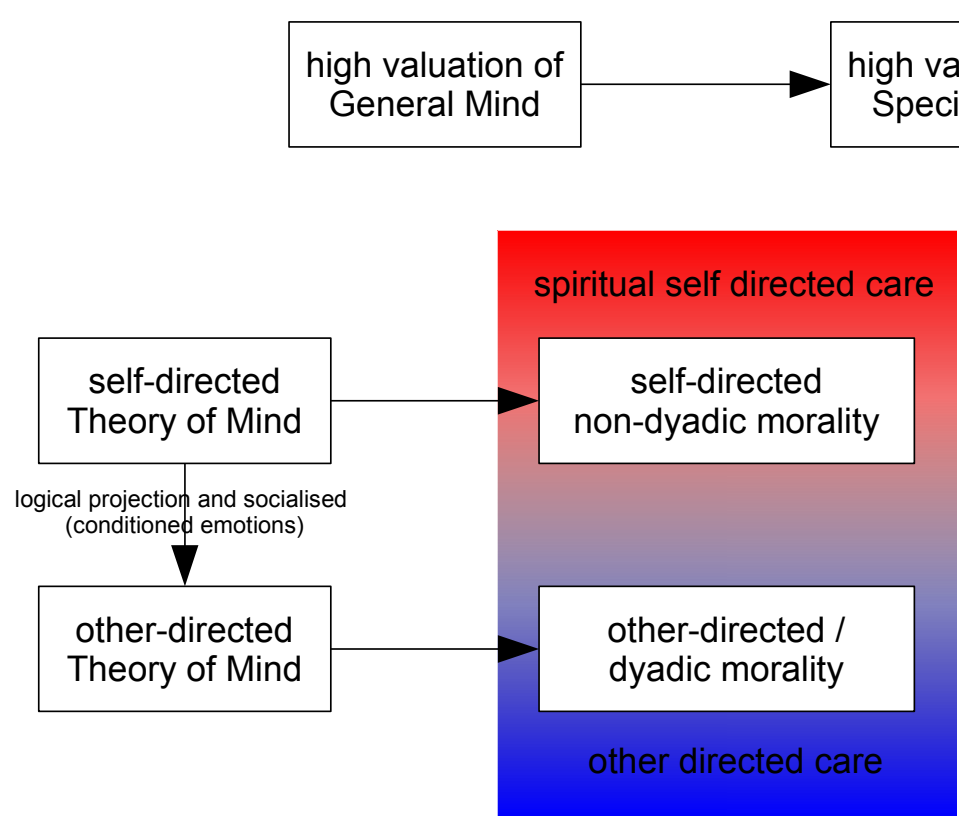

Figure 1. Diagram of the model of morality proposed.

Furthermore, even within dyadic frameworks, it has been argued that non-dyadic morality exists; the perception of spiritual suffering, tainting of the soul (immoral soul), and harm to future self [13, 14]. It is not clear how such ostensibly harmless acts could come to be judged as immoral in the first place if dyadic morality was the only mechanism (there is no self-directed component). Likewise, it is not clear that the lack of belief in a physically independent soul should necessarily negate a perception of harm 
to spiritual self, or whether such a response is dependent on a belief in a deity (see [14]). Cross-cultural evidence suggests morality extends beyond interpersonal interaction and behaviour, to the self and thought alone (including contemplative monotheism, eastern religion, native American traditions, and both eastern and western philosophy). As such, self-directed processes may be involved.

Consistent with dyadic models, evidence suggests that intent perception is a cross-cultural determinant of moral judgements [15]. The mitigating factor of 'necessity' (doing harm to help another) exhibited universal applicability in the severity of moral judgements (across nine societies). Yet evidence suggests there is little influence of intent perception on purity domain judgements [16. This is consistent with the purity foundation being self-directed. Other-directed morality is intent dependent, as someone might do something harmful to another to help someone else. But there are few realistic circumstances in which one must defile oneself (purity violation) to help another person.

Respect for non-spiritual self is not here connected to the moral construct, as it is maintained by natural instinct for self-preservation, and often conflicts with respect for spiritual self and others. It may well be something which morality is defined in opposition to (selfishness). Similarly, variation in moral valuation will not be examined here in detail, but the theory predicts such relates to the number of minds one believes in, and one's perspective on those minds. Belief in mind as an exclusive feature of humanity might lead to species based moral discrimination. Belief in gods for example might lead to variations in expectations of mental significance (perhaps mediated by metaphysical libertarianism). Likewise, one can value a significant mind (significance of mind); the mind of a specific individual, without greatly valuing neutral (general) mind in comparison; yet their valuation should be associated. Furthermore, morality will vary based on differential valuations of spiritual self and other directed care. Again, this may be a dimension upon which immorality emerges (the extremes of which might be seen as evil).

\section{Preliminary Analysis}

Moral Foundations occlusion data from study 1 were used to perform preliminary testing of the model's predictions for self and other-directed morality. In this analysis, a set of explicit harm foundation measures were taken to represent dyadic (other-directed) morality, and a set of explicit purity foundation measures were taken to represent self-directed morality. The use of care and purity is not an ideal nomenclature given that the harm foundation is not exclusively dyadic, and the purity foundation is not exclusively self-directed. Ideally, self-directed and other-directed care would be measured, but the implementation of specialised measures limits cross-examination between models. Likewise, as this information does not perfectly map to the moral foundations, it was extracted using individual measures thereof. Furthermore, explicit foundation measures were desired based on the test of explicit morality, and to prevent replication of any cultural or content biases in the official measures (e.g. Moral Foundations Questionnaire; [17]). The information is known to be represented within (at least) the harm and purity foundations respectively, and these were therefore chosen for taxonomy analysis.

A number of conditions were examined. Firstly, the basic predictions of Moral Dyad theory [1] and the model proposed were tested; whether morality could be explained in terms of both other-directed (care) and self-directed (purity) components. The purity foundation's care independent association with morality was also tested to this end. Furthermore, the two foundation taxonomy provided by the model (dyadic/self-directed) was tested against a one foundation taxonomy (Moral Dyad theory) and five foundation taxonomy (Moral Foundations theory); comparing the coefficient of determination of each taxonomy and applying Occam's razor. Likewise, the dissociation predicted by 
Haidt and Joseph [2] between the individualising and binding foundations was tested. Finally, the self-directed care construct was examined in more detail. Although non-exclusively dyadic (other-directed) significance of mind measures were used to test the primary hypotheses (integrity, and being true to yourself and others), study 1 P6 (and study 2) added purity neutral self-directed significance of mind measures. This enabled the theory to be further tested against that of both Gray et al. [1] and Haidt and Joseph [2], indicating whether the purity foundation might actually be representative of a more general construct capturing self-directed morality.

The predictions of the model for self and other-directed morality were supported.

All non-harm foundation morality was found to be mediated by the perception of harm, as predicted by the Moral Dyad theory of Gray et al. [1]. The association between valuation of the non-harm foundations and morality was partially mediated by valuation of the harm foundation in all parts (P1, P2, P3, P4 and P6), and across all non-harm foundations. See Table 2.

Note mediation analysis could not be performed with P5 data due to the limited number of moral foundations tested. Likewise, P4 tested specific instances of moral foundations, rather than general moral concepts, which appears to have limited the concept of harm and prevented its generalisation across foundations. The association between morality and valuation of the harm foundation was significantly lower in P4 than all other parts (and lower than the association between morality and all other foundations in P4). Its 'protecting another person in danger' measure of the harm foundation may have been less valued (and less associated with morality) because it invoked prospects of putting oneself in harm's way (confounding risk to self). As such, for all analyses, the original fairness measure in P4 ('supporting another person in need') was taken as the dyadic morality measure instead of the original harm measure.

Regression analysis from all parts indicated that morality was uniquely predicted by both dyadic (care) and self-directed (purity) morality. See Table 3 . The fact there is a component of morality not explained by care but explained by purity indicates that there are likely to be self-directed processes contributing to morality. Likewise, supporting the choice of measures for dyadic and self-directed morality, the purity and harm foundations were found to be relatively independent. The association between the purity foundation (as compared to all other foundations) and morality was more weakly mediated by the harm foundation (no causal assumption). Its average association with morality (after partialling out care) was $r=0.32$, versus $0.23,0.25$, and 0.22 (for the fairness, authority, and loyalty foundations respectively; across parts P1, P2, P3, P4, and P6). Contrary to Gray et al. [1, this supports the assumption that the purity foundation is acting as a self-directed morality (significance of mind) measure.

Furthermore, a two foundation taxonomy explained variance in explicit morality better than a one foundation taxonomy (Moral Dyad theory), and near equal to a five foundation taxonomy (Moral Foundations theory). Averaged across parts P1, P2, P3, $\mathrm{P} 4$, and $\mathrm{P} 6$, the fractional variance explained was $R^{2}=0.27,0.36$, and 0.40 , for the one, two, and five foundation models respectively. See Table 4. Although it is not possible to identify the reason for the short fall in variance explanation between the two and five foundation taxonomies ( $10 \%$ averaged), it is possible that this relates to the dyadic (care) and self-directed (purity) morality measures being estimates of the constructs (as opposed to being specially designed). Likewise, it is clear that a domain general mechanism (one foundation taxonomy) explains the majority of the variance in moral valuation as compared with more complex models (68\% averaged). It is possible however that self-directed care is partially captured by the dyadic morality measures (explicit harm foundation/care), making the dyadic morality measures somewhat synonymous with morality (according to the model proposed).

In accordance with Haidt and Joseph [2], a dissociation was observed between 
valuation of the individualising (harm/fairness) and binding (purity/authority)

foundations. This dissociation is consistent with a two foundation taxonomy. See Fig. 1.

Factor analysis confirmed this dissociation (parts P1, P2, P3, P4, and P6), with the

first factor being representative of all foundations (general morality), and the second factor distinguishing between the binding and the individualising foundations. See Table 5. The loyalty foundation (explicit loyalty) and the alternate measure of the authority foundation (explicit honour) were however more associated with the individualising than the binding foundations. This discrepancy is consistent with the supposition that loyalty and authority can be interpreted either as other or self directed care, whereas the purity foundation remains primarily self-directed. It cannot however be used to critique the development of the five foundation taxonomy with respect to its four foundation predecessor [18 20, given that ingroup loyalty was not specifically tested. Likewise, liberals valued the binding foundations less than conservatives (significant in most parts), and the individualising foundations more than conservatives (non-significant in most parts). See Fig. 2. Again, this supports the relevance of a two foundation taxonomy of morality. Furthermore, the overall valuation of the individualising foundations was higher than that of the binding foundations (even for conservatives). Similarly, this is consistent with a two foundation taxonomy.

Finally, the purity neutral self-directed significance of mind measures were associated with morality (see Table 2 of the main text; contemplation, conscience). The self-directed explicit purity measures were however more strongly associated with morality than the purity foundation neutral self-directed significance of mind measures (see Table 3 of S4 Appendix), although this difference was non-significant for the one part in which both were present $(\mathrm{P} 6)$.

Table 1. Moral foundation explicit measures

\begin{tabular}{|l|r|r|r|r|r|}
\hline & Harm & Fairness & Authority & Loyalty & Purity \\
\hline S1 P1 & safety & equality & authority & loyalty & purity \\
S1 P2 & prevention of harm & fairness & authority & loyalty & loyalty \\
S1 P3 & care & fairness & honour & sanctity \\
S1 P4 & protecting another & supporting another & obeying another & being loyal to & maintaining \\
& person in danger & person in need & person in authority & another person & yourself in purity \\
S1 P5 & care & equality & N/A & N/A & N/A \\
S1 P6 & care & fairness & authority & loyalty & chastity \\
S1 P6 & harming others & cheating others & subverting others & betraying others & degrading oneself \\
(neg) & & & & & \\
\hline
\end{tabular}


Table 2. Association between the non-harm foundations and morality (as mediated by the harm foundation)

\begin{tabular}{|c|c|c|c|c|c|c|c|c|c|c|}
\hline \multirow[t]{2}{*}{ Foundation } & \multicolumn{5}{|c|}{ Association with morality (wo care) } & \multicolumn{5}{|c|}{ Association with morality (w care) } \\
\hline & $\beta(\mathbf{r})$ & df & $p$ & CImin & CImax & $\beta$ & $\mathrm{df}$ & $p$ & CImin & CImax \\
\hline \multicolumn{11}{|l|}{ S1 P1 } \\
\hline care & 0.41 & 148 & $<.001$ & 0.26 & 0.53 & & & & & \\
\hline fairness & 0.29 & 148 & $<.001$ & 0.14 & 0.43 & 0.14 & 147 & .088 & -0.02 & 0.31 \\
\hline authority & 0.28 & 148 & $<.001$ & 0.13 & 0.42 & 0.20 & 147 & .011 & 0.05 & 0.35 \\
\hline loyalty & 0.37 & 148 & $<.001$ & 0.22 & 0.50 & 0.22 & 147 & .009 & 0.06 & 0.39 \\
\hline purity & 0.30 & 148 & $<.001$ & 0.15 & 0.44 & 0.18 & 147 & .024 & 0.02 & 0.34 \\
\hline \multicolumn{11}{|l|}{ S1 P2 } \\
\hline care & 0.60 & 148 & $<.001$ & 0.48 & 0.69 & & & & & \\
\hline fairness & 0.45 & 148 & $<.001$ & 0.31 & 0.57 & 0.23 & 147 & .002 & 0.09 & 0.37 \\
\hline authority & 0.37 & 148 & $<.001$ & 0.22 & 0.50 & 0.25 & 147 & $<.001$ & 0.12 & 0.38 \\
\hline loyalty & 0.39 & 148 & $<.001$ & 0.25 & 0.52 & 0.11 & 147 & .174 & -0.05 & 0.26 \\
\hline purity & 0.47 & 148 & $<.001$ & 0.33 & 0.58 & 0.31 & 147 & $<.001$ & 0.18 & 0.44 \\
\hline \multicolumn{11}{|l|}{ S1 P3 } \\
\hline care & 0.55 & 148 & $<.001$ & 0.42 & 0.65 & & & & & \\
\hline fairness & 0.32 & 148 & $<.001$ & 0.17 & 0.46 & 0.07 & 147 & .349 & -0.08 & 0.23 \\
\hline authority & 0.40 & 148 & $<.001$ & 0.26 & 0.53 & 0.16 & 147 & .040 & 0.01 & 0.32 \\
\hline loyalty & 0.35 & 148 & $<.001$ & 0.20 & 0.48 & 0.17 & 147 & .022 & 0.03 & 0.31 \\
\hline purity & 0.56 & 148 & $<.001$ & 0.44 & 0.66 & 0.41 & 147 & $<.001$ & 0.28 & 0.54 \\
\hline \multicolumn{11}{|l|}{ S1 P4 } \\
\hline care & 0.37 & 160 & $<.001$ & 0.23 & 0.50 & & & & & \\
\hline fairness & 0.49 & 160 & $<.001$ & 0.36 & 0.60 & 0.43 & 159 & $<.001$ & 0.25 & 0.62 \\
\hline authority & 0.45 & 160 & $<.001$ & 0.31 & 0.56 & 0.38 & 159 & $<.001$ & 0.24 & 0.52 \\
\hline loyalty & 0.50 & 160 & $<.001$ & 0.37 & 0.60 & 0.42 & 159 & $<.001$ & 0.26 & 0.59 \\
\hline purity & 0.52 & 160 & $<.001$ & 0.40 & 0.62 & 0.47 & 159 & $<.001$ & 0.34 & 0.60 \\
\hline \multicolumn{11}{|l|}{ S1 P5 } \\
\hline care & 0.58 & 124 & $<.001$ & 0.45 & 0.69 & & & & & \\
\hline \multicolumn{11}{|l|}{ S1 P6 } \\
\hline care & 0.48 & 218 & $<.001$ & 0.37 & 0.58 & & & & & \\
\hline fairness & 0.40 & 218 & $<.001$ & 0.28 & 0.50 & 0.25 & 217 & $<.001$ & 0.15 & 0.42 \\
\hline authority & 0.36 & 218 & $<.001$ & 0.24 & 0.47 & 0.25 & 217 & $<.001$ & 0.13 & 0.37 \\
\hline loyalty & 0.36 & 218 & $<.001$ & 0.24 & 0.47 & 0.17 & 217 & .009 & 0.04 & 0.30 \\
\hline purity & 0.37 & 218 & $<.001$ & 0.25 & 0.48 & 0.25 & 217 & $<.001$ & 0.13 & 0.37 \\
\hline
\end{tabular}


Table 3. Regression analysis of morality as predicted by dyadic (care) and self-directed (purity) morality

\begin{tabular}{|l|r|r|r|r|r|r|}
\hline Foundation & sr & df & t & p & CImin & CImax \\
\hline S1 P1 & & & & & & \\
\hline care & 0.32 & 147 & 4.36 & $<.001$ & 0.18 & 0.46 \\
purity & 0.17 & 147 & 2.29 & .024 & 0.03 & 0.31 \\
\hline S1 P2 & & & & & & \\
\hline care & 0.47 & 147 & 7.64 & $<.001$ & 0.36 & 0.58 \\
purity & 0.30 & 147 & 4.78 & $<.001$ & 0.18 & 0.41 \\
\hline S1 P3 & & & & & & \\
\hline care & 0.35 & 147 & 5.60 & $<.001$ & 0.23 & 0.46 \\
purity & 0.37 & 147 & 6.05 & $<.001$ & 0.26 & 0.49 \\
\hline S1 P4 & & & & & & \\
\hline care & 0.38 & 159 & 6.33 & $<.001$ & 0.27 & 0.50 \\
purity & 0.42 & 159 & 7.02 & $<.001$ & 0.31 & 0.54 \\
\hline S1 P6 & & & & & & \\
\hline care & 0.38 & 217 & 6.70 & $<.001$ & 0.28 & 0.49 \\
purity & 0.23 & 217 & 4.07 & $<.001$ & 0.12 & 0.34 \\
\hline
\end{tabular}

Table 4. Regression analysis of morality as predicted by various models $(1,2$, and 5 foundation taxonomies)

\begin{tabular}{|l|r|r|r|}
\hline & Model 1 (Dyadic) & Model 2 (Dyadic / Self-directed) & Model 3 (Moral Foundations) \\
\hline & harm $\left(R^{2}\right)$ & harm/purity $\left(R^{2}\right)$ & $\mathbf{H} / \mathbf{F} / \mathbf{A} / \mathbf{L} / \mathbf{P}\left(R^{2}\right)$ \\
\hline S1 P1 & 0.17 & 0.19 & 0.25 \\
S1 P2 & 0.35 & 0.44 & 0.48 \\
S1 P3 & 0.30 & 0.44 & 0.44 \\
S1 P4 & 0.24 & 0.42 & 0.46 \\
S1 P5 & 0.34 & N/A & N/A \\
S1 P6 & 0.23 & 0.29 & 0.36 \\
S1 P6 (neg) & 0.09 & 0.28 & 0.33 \\
\hline
\end{tabular}

Table 5. Factor analysis of moral foundations (dissociation between individualising and binding foundations)

\begin{tabular}{|l|r|r|r|r|r|r|}
\hline & \% of variance & Harm & Fairness & Loyalty & Authority & Purity \\
\hline S1 P1 & & & & & & \\
\hline factor 1 & 44.04 & 0.79 & 0.62 & 0.73 & 0.51 & 0.63 \\
factor 2 & 22.73 & 0.18 & 0.54 & 0.27 & -0.68 & -0.52 \\
\hline S1 P2 & & & & & & \\
\hline factor 1 & 48.73 & 0.74 & 0.70 & 0.78 & 0.61 & 0.65 \\
factor 2 & 17.66 & -0.44 & -0.30 & -0.17 & 0.62 & 0.44 \\
\hline S1 P3 & & & & & & \\
\hline factor 1 & 52.69 & 0.78 & 0.69 & 0.67 & 0.81 & 0.68 \\
factor 2 & 15.41 & 0.26 & 0.57 & -0.58 & -0.10 & -0.18 \\
\hline S1 P4 & & & & & & \\
\hline factor 1 & 53.18 & 0.79 & 0.84 & 0.83 & 0.61 & 0.52 \\
factor 2 & 23.08 & -0.36 & -0.32 & -0.22 & 0.60 & 0.71 \\
\hline S1 P6 & & & & & & \\
\hline factor 1 & 45.92 & 0.73 & 0.60 & 0.73 & 0.65 & 0.67 \\
factor 2 & 21.50 & -0.25 & -0.53 & -0.33 & 0.57 & 0.55 \\
\hline
\end{tabular}




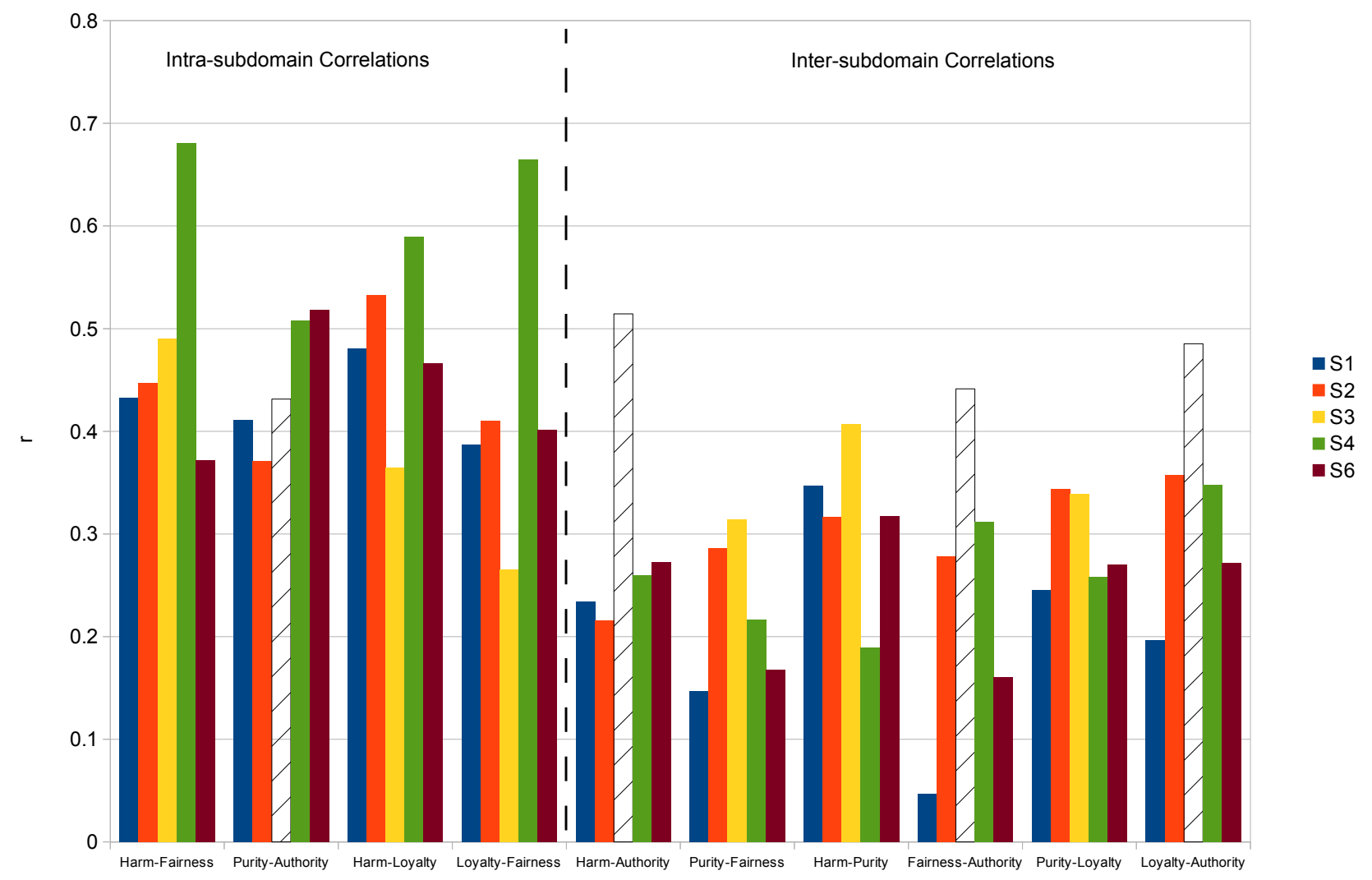

Figure 2. Correlations between valuation of the individualising and the binding foundations. 


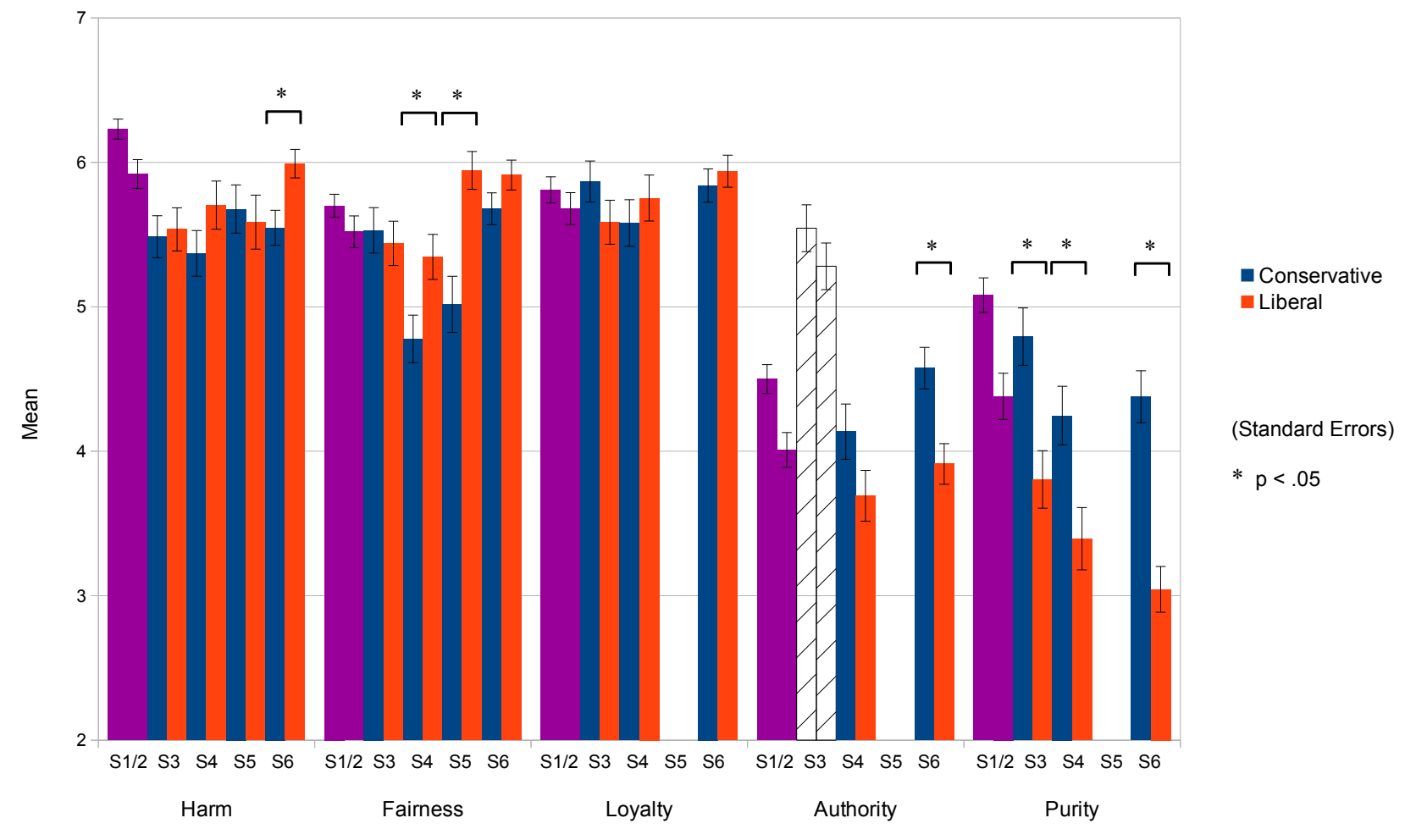

Figure 3. Mean valuations of the moral foundations, separated by political orientation (conservative and liberal). 


\section{Discussion}

The predictions of the model for self and other-directed morality were supported by study 1. Regression analysis from all six parts indicated that morality was explained by both dyadic (care) and self-directed (purity) morality. Likewise, the purity foundation's association with morality was less strongly mediated by its association with the harm foundation (than all other foundations), supporting the assumption that the purity foundation functions as a self-directed morality (significance of mind) measure. Furthermore, a two foundation taxonomy (dyadic/explicit harm and self-directed/explicit purity) predicted morality better than a one foundation taxonomy (dyadic/explicit harm: Moral Dyad theory), and near equal to a five foundation taxonomy (explicit foundations: Moral Foundations theory). Finally, a dissociation was observed between the individualising and binding foundations.

\section{Supporting Information}

\section{S1 Appendix}

\section{S2 Appendix}

\section{S3 Appendix}

\section{S4 Appendix}

\section{S5 Appendix}

\section{S6 Appendix}

\section{S7 Appendix}

\section{References}

1. Gray K, Young L, Waytz A. Mind perception is the essence of morality. Psychological Inquiry. 2012;23(2):101-124.

2. Haidt J, Joseph C. Intuitive ethics: How innately prepared intuitions generate culturally variable virtues. Daedalus. 2004;133(4):55-66.

3. Gray K, Wegner DM. Moral typecasting: divergent perceptions of moral agents and moral patients. Journal of personality and social psychology. 2009;96(3):505.

4. Holland E. From somebodies to bodies: towards a better understanding of the causes, process, and consequences of sexual objectification; 2013.

5. H Gray HM, Gray K, Wegner DM. Dimensions of mind perception. Science. 2007;315(5812):619-619.

6. James W. The principles of psychology. vol. vols. I and II. New York: Dover; 1950.

7. Graham J, Haidt J, Nosek BA. Liberals and conservatives rely on different sets of moral foundations. Journal of Personality and Social Psychology. 2009;96(5):1029-1046. 
8. Shweder R, Much N, Mahapatra M, Park L. The "Big Three" of morality (autonomy, community, divinity) and the "Big Three" explanations of suffering. In: Brandt A, Rozin P, editors. Morality and health. Psychology Press; 1997. p. 119-169.

9. Chakroff A, Dungan J, Young L. Harming ourselves and defiling others: what determines a moral domain? PloS one. 2013;8(9):e74434.

10. Graham J, Nosek B, Haidt J, Iyer R, Koleva S, Ditto P. Mapping the Moral Domain. Journal of personality and social psychology. 2011 Aug;101(2):366-385.

11. Haidt J. The new synthesis in moral psychology. Science. 2007 May;316(5827):998-1002.

12. Haidt J. Morality. Perspectives on psychological science. 2008;3(1):65-72.

13. Gray K, Schein C, Ward AF. The myth of harmless wrongs in moral cognition: Automatic dyadic completion from sin to suffering. Journal of Experimental Psychology: General. 2014;143(4):1600.

14. Schein C, Gray K. The unifying moral dyad: Liberals and conservatives share the same harm-based moral template. Personality and Social Psychology Bulletin. 2015;p. 0146167215591501.

15. Barrett HC, Bolyanatz A, Crittenden AN, Fessler DM, Fitzpatrick S, Gurven M, et al. Small-scale societies exhibit fundamental variation in the role of intentions in moral judgment. Proceedings of the National Academy of Sciences. 2016;113(17):4688-4693.

16. Young L, Saxe R. When ignorance is no excuse: Different roles for intent across moral domains. Cognition. 2011;120(2):202-214.

17. Gray K, Keeney J. Impure, or Just Weird? Scenario Sampling Bias Raises Questions about the Foundation of Morality. Social Psychology and Personality Science. 2015;.

18. Haidt J, Graham J. When morality opposes justice: Conservatives have moral intuitions that liberals may not recognize. Social Justice Research. 2007;20(1):98-116.

19. Haidt J, Craig J. The moral mind: How five sets of innate intuitions guide the development of many culture-specific virtues, and perhaps even modules. In: P Carruthers SL, Stich S, editors. The Innate Mind. vol. 3. Oxford University Press, USA; 2007. .

20. Haidt J, Bjorklund F. Social intuitionists answer six questions about morality. In: Sinnott-Armstrong W, editor. Moral psychology, Vol. 2: The cognitive science of morality. vol. 2. Cambridge, MA: MIT Press; 2008. p. 181-217. 


\section{S6 Appendix - Changes between study parts}

\section{Study 1}

Study 1 parts P1 to P6 differed from each other in the selection of dummy variables, the measures used to valuate neutral mind and significance of mind, the range of the Likert scales, the ordering of the items, the number of occlusion variables tested, and the number of moderators tested.

A variety of dummy variables were inserted into the surveys to filter bad participant data. This process is discussed in S3 Appendix.

Measures of neutral mind were created to capture (reference) 'mind' in the first person folk psychological sense (philosophy of mind; whether property or substance dualism), rather than in the context of intellect (information processing) or its physical correlate (brain processes); observables studied by the empirical method. In the event participants were interpreting "mind" as 'intellect' in P1, this measure was replaced with "sentience (consciousness)" in P2. P3 made a further modification by changing this measure to "our mind (awareness)", under the assumption people generally do not associate the phrase "our mind" with 'intellect'. P4 used a further variation of the measure, adopting "yourself (existence)", to emphasise the subjective nature of the concept being queried, although its neutrality is questionable (as it relates to self-esteem). P5 used yet another variation of the measure, "mind (consciousness)". P6 used a final variation of the measure, "mind (sentience)".

The primary significance of mind measure used throughout the parts was chosen as 'integrity' (based on its literal association with both dyadic and non-dyadic morality). P4 introduced an alternative significance of mind measure, "being true to yourself and others", intending to represent a specific application of integrity. Study 1 P6 was designed to test additional, purity foundation neutral self-directed measures of significance of mind based on the positive results from study 2 (manipulating the perceived scope and intensity of thought). P6 also measured the association between immorality ("how bad do you consider immorality") and a negative significance of mind measure ("how bad do you consider not thinking about others").

The seven level Likert scale in P2 was "positively" skewed (with respect to that used in P1) in an attempt to better capture fine variations in user valuation of the set (of what happen to be entirely positive items). In addition to this, numerical headings were added to each option to ensure participants interpreted the options as continuously increasing in value. The $\mathrm{P} 1$ multiple choice options "not at all valuable... utmost value" were changed to " 1 . not very valuable... 7. utmost value" for P2. The multiple choice option "3. significantly valuable" in P2 was changed to "3. valuable" in P3 (to prevent a participant misinterpreting 'significantly' as 'greatly'). The multiple choice option "7. utmost value" was changed to " 7 . most extreme value" in P4 and P5 (to explicate the meaning of utmost). P6 again changed option "3. valuable" to "3. quite valuable" for multiword consistency (and to prevent provision of an easy almost-always-correct option for tired or less interested participants).

Furthermore, the ordering of the items was changed between each part (see S2 Appendix. This also included, as discussed, normal and reverse ordering of the list for parts $\mathrm{P} 5$ and $\mathrm{P} 6$.

Likewise, the number of occlusion variables was changed between parts. The explicit moral foundations are listed in Table 1 of S5 Appendix.

Finally, the number of moderators tested was changed between parts. Gender was measured into parts $\mathrm{P} 3, \mathrm{P} 4$, and $\mathrm{P} 6$, and political orientation was measured in parts $\mathrm{P} 3$, $\mathrm{P} 4, \mathrm{P} 5$, and $\mathrm{P} 6$. 


\section{Study 3}

Study 3 P1, P2, P3, and P4 replicated the effect for hypothesis 3, differing only in the precise wording of the questions.

In study $3 \mathrm{P} 2$, question 1 (Morality applies to) option 2 was changed from 'all creatures with a mind' to 'all creatures with a mind (including humans)' to ensure participants were interpreting the word "creature" in this context to include human beings (i.e. correctly). It was evident many participants (approximately 9\%) did not include human beings in the category of creature in the first part (A), based on the difference between these results.

Furthermore, in P1 and P2, some participants may have interpreted question 2 ("Do only human beings have a mind?") as pertaining also to supernatural beings (not just human beings and creatures, as per its initial context/question 1). This could have affected the number of people calculated as having considered the application of morality relevant to all and only creatures with minds. Therefore P3 and P4 addressed this by adding additional information to options, yes; "(human beings only)", and no; "(some other creatures also)".

Study 3 P3 used the first 2 questions from P1 and P2 (with the modification of question 2 explained above). P3 was designed to replicate P1 and P2 (discarding political orientation and gender information). P4 maintained all questions from P1 and P2 (except for the integrity definition, question 5, and the above modification of question 2), along with a new question ("Do all creatures have a mind?"). This new question was added to verify in the case the participant responded "all creatures" (option 1) to 'Morality applies to' (question 1), whether they merely thought all creatures had a mind, and could therefore have responded "all creatures with a mind (including humans)" (option 2) instead. P4 was therefore designed to more accurately gauge the percentage of participants who viewed morality as applying exclusively to creatures with minds.

\section{Supporting Information}

\section{S1 Appendix}

\section{S2 Appendix}

\section{S3 Appendix}

\section{S4 Appendix}

\section{S5 Appendix}

\section{S6 Appendix}

\section{S7 Appendix}




\section{S7 Appendix - Moderators}

\section{Study 1}

Gender and political orientation based moderation of the results from study 1 was analysed.

With respect to hypothesis $1 \mathrm{~A}$, the association between neutral mind and morality was consistently weaker for liberal males across all parts (P3, P4, and P6). In P3, the association between our mind (awareness) and morality was marginally significantly lower for liberal males $(r(31)=0.21, p=.25,95 \%$ CI [-0.14, 0.52]), compared to conservative males $(r(29)=0.45, p<.001,95 \%$ CI $[0.11,0.69])$, conservative females $(r(35)=0.59, p<.001,95 \%$ CI [0.33, 0.77]), and liberal females $(r(47)=0.38, p=$ $.007,95 \%$ CI $[0.11,0.60])$. In $\mathrm{P} 4$, the association between yourself (existence) and morality was significantly lower for liberal males $(r(30)=0.06, p=.745,95 \%$ CI $[-0.30$, $0.40])$, compared to conservative males $(r(31)=0.58, p<.001,95 \%$ CI [0.29, 0.77]), conservative females $(r(46)=0.54, p<.001,95 \%$ CI [0.30, 0.71]), and liberal females $(r(47)=0.53, p<.001,95 \%$ CI $[0.30,0.71])$. In P6, the association between mind (sentience) and morality was significantly lower for liberal males $(r(40)=-0.12, \mathrm{p}=$ $0.435,95 \%$ CI $[-0.41,0.19])$, compared to conservative males $(r(42)=0.30, \mathrm{p}=0.049$, $95 \%$ CI $[0.00,0.55])$, conservative females $(r(60)=0.36, p=.004,95 \%$ CI $[0.12,0.56])$, and liberal females $(r(70)=0.33, \mathrm{p}=0.004,95 \%$ CI $[0.11,0.53])$. Consistent with this trend, the association between value of mind (consciousness) and value of morality in $\mathrm{P} 5$ was stronger for conservatives $(r(124)=0.41, p<.001,95 \%$ CI $[0.25,0.54])$ than liberals $(r(128)=0.29, p<.001,95 \%$ CI $[0.13,0.44])$, albeit non-significant.

With respect to hypothesis $1 \mathrm{~B}$, the association between morality and integrity was consistently stronger for females across all parts (P3 and P6). No consistent difference in political orientation was observed. In P3, the association between value of integrity and value of morality was significantly stronger for females $(r(84)=0.70, p<.001,95 \%$ CI $[0.58,0.80])$ than for males $(r(62)=0.50, p<.001,95 \%$ CI $[0.32,0.64])$. This gender difference appeared to be retained irrespective of political orientation (although it was associated more strongly for conservatives in this part), between both conservative males $(r(29)=0.66, p<.001,95 \%$ CI $[0.39,0.82])$, and conservative females $(r(35)=0.83, p<.001,95 \%$ CI $[0.69,0.91])$, and liberal males $(r(31)=0.40, p$ $=.020,95 \%$ CI $[0.07,0.65])$ and liberal females $(r(47)=0.58, p<.001,95 \%$ CI $[0.35$, 0.74]). Likewise in $\mathrm{P} 6$, the association between morality and integrity was significantly higher for females $(r(132)=0.53, p<.001,95 \%$ CI $[0.39,0.64])$ than males $(r(84)=$ $0.37, p<.001,95 \%$ CI $[0.17,0.54])$. This trend was observed for both conservatives and liberals; conservative females $(r(60)=0.55, p<.001,95 \%$ CI $[0.34,0.70])$ versus conservative males $(r(42)=0.42, p=.005,95 \%$ CI [0.14, 0.63]), and liberal females $(r(70)=0.52, p<.001,95 \%$ CI $[0.32,0.67])$ versus liberal males $(r(40)=0.34, p=$ $.026,95 \%$ CI $[0.04,0.59])$.

\section{Study 2}

With respect to hypothesis 2 , no significant differences were found in gender and political orientation within the significance of mind manipulation conditions. The t-test results are provided in tables 1 and 2 for political orientation and gender respectively.

\section{Study 3}

With respect to hypothesis 3 , there were no significant differences found in gender and political orientation for the number of people who considered the application of morality 
Table 1. Study 2 t-test Table - Political Orientation

\begin{tabular}{|l|r|r|r|}
\hline & $\mathbf{t}$ & $\mathbf{d f}$ & $\mathbf{p}$ \\
\hline Manipulation A (thought - negative) & -0.56 & 59 & .580 \\
Manipulation B (thought - positive) & 0.10 & 54 & .918 \\
Manipulation C (care - negative) & 1.96 & 42 & .056 \\
Manipulation D (care - positive) & -1.62 & 54 & .110 \\
Control & -1.57 & 42 & .124 \\
\hline
\end{tabular}

Table 2. Study 2 t-test Table - Gender

\begin{tabular}{|l|r|r|r|}
\hline & $\mathbf{t}$ & $\mathbf{d f}$ & $\mathbf{p}$ \\
\hline Manipulation A (thought - negative) & 0.88 & 59 & .386 \\
Manipulation B (thought - positive) & -0.31 & 54 & .760 \\
Manipulation C (care - negative) & 0.61 & 42 & .548 \\
Manipulation D (care - positive) & 1.29 & 54 & .202 \\
Control & -.04 & 41 & .968 \\
\hline
\end{tabular}

relevant to all and only creatures with minds versus the number of people who thought otherwise.

The number of people who considered the application of morality relevant to all and only creatures with minds was consistently higher for both conservatives (compared with liberals), and males (compared with females), however these main effects were non-significant in all parts (P2 and P4). In P2, there was no significant difference between conservatives and liberals in the number of people who considered the application of morality relevant to all and only creatures with minds ( $53 \%$ vs $46 \%$ ), versus the number of participants who thought otherwise $(47 \%$ vs $54 \%) ; \chi^{2}(1, \mathrm{~N}=99)$ $=.49, p=.486$. In $\mathrm{P} 4$, there was no significant difference between conservatives and liberals in the number of people who considered the application of morality relevant to all and only creatures with minds ( $58 \%$ vs $52 \%$ ), versus the number of participants who thought otherwise $(42 \%$ vs $48 \%) ; \chi^{2}(1, \mathrm{~N}=150)=.52, p=.473$. In P2, there was no significant difference between males and females in the number of people who considered the application of morality relevant to all and only creatures with minds ( $57 \%$ vs $42 \%$ ), versus the number of participants who thought otherwise ( $43 \%$ vs $58 \%$ ); $\chi^{2}(1, \mathrm{~N}=99)=2.27, p=.132$. In $\mathrm{P} 4$, there was no significant difference between males and females in the number of people who considered the application of morality relevant to all and only creatures with minds ( $57 \%$ vs $53 \%$ ), versus the number of participants who thought otherwise $(43 \%$ vs $47 \%) ; \chi^{2}(1, \mathrm{~N}=150)=.21, p=.651$. 